Article

\title{
A Synthesis on the Effects of Two Commercial Recycled Plastics on the Properties of Bitumen and Asphalt
}

\author{
Greg White \\ School of Science and Engineering, University of the Sunshine Coast, Sunshine Coast, QLD 4561, Australia; \\ gwhite2@usc.edu.au; Tel.: +61-400-218-048
}

Received: 7 September 2020; Accepted: 14 October 2020; Published: 16 October 2020

check for updates

\begin{abstract}
The desire to develop sustainable infrastructure, including pavement structures and materials, is ever increasing in recent times. One opportunity is to partially replace high-cost bituminous binder with low-cost recycled plastic in asphalt mixtures. This synthesis combines the various research efforts to understand the effects of two commercially available recycled plastics, known as MR6 and MR10, on bituminous binders and asphalt mixtures. Using common test methods from the United Kingdom, the United States and Australia, generally consistent and significant effects were observed in various base bitumen grades and various common asphalt mixture types. Binder resistance to flow and binder elasticity both increased significantly and were associated with the three to four grade increases under the Performing Grading system. Similarly, mixture stiffness and mixture resistance to deformation increased significantly, while crack resistance and moisture damage resistance were not significantly affected. The effects of MR6 and MR10 were generally similar to the effects associated with conventional polymer modification of asphalt binders and asphalt mixtures, particularly those effects associated with plastomeric polymers.
\end{abstract}

Keywords: recycled; plastic; bitumen; asphalt

\section{Introduction}

The desire to develop sustainable infrastructure, including pavement structures and materials, is ever increasing in recent times [1]. Given the diversity of pavement structures, which can include cement concrete, asphalt mixtures, granular crushed rock, and natural gravels, the opportunities for sustainable pavement construction are broad and many. When considering sustainability opportunities, it is important to take into account the effect on the durability and expected life of the pavement, as well as the reduction in financial or environmental cost of the more sustainable solution [2]. That is, an initiative that reduces the new pavement's greenhouse gas emissions by $20 \%$ is not really sustainable if the pavement only lasts $50 \%$ of the life of the conventional solution [3]. It is also important to understand that sustainability initiatives are only viable if the cost to collect, process, and reincorporate a recycled material or product is less expensive than the cost of the material or product that it replaces [4]. For this reason, the replacement of high-cost materials, such as bituminous binder, and cement, with recycled or repurposed materials is a great interest.

One opportunity is to replace high-cost bituminous binder with low-cost recycled plastic in asphalt mixtures [1]. However, there are many types and forms of recycled plastic and only a few of them are well suited to recycling in asphalt mixtures [5]. As detailed later, some researchers and practitioners have recycled plastic into asphalt mixtures in many diverse ways, ranging from simply shredding plastic containers, crates or car bumpers and adding them to asphalt mixture production, right through the depolymerization of waste plastic and blending of the recovered raw polymers into bituminous binder [6]. 
This paper presents a synthesis of research on two commercially available recycled plastic products for the modification and extension of bituminous binders in asphalt mixture production. The aim is to provide a summary of the effects of the two products on bitumen and asphalt and to consider the general trends found across various research efforts. The products, known as MR6 and MR10, are intended to be plastomeric and elastomeric, respectively. This synthesis is focused on the physical and mechanical properties of the bituminous binder and asphalt mixtures produced with both recycled plastic products. Environmental and practical issues, such as leaching, fuming, and storage stability, are not addressed here.

\section{Background}

\subsection{Use of Recycled Plastic in Road Pavements}

Many countries have now reported the use of recycled plastic in asphalt mixture production, either as an aggregate extender, a bitumen extender, or a binder modifier. For example, Vancouver (Canada) incorporated plastic crate waste as a warm mixed asphalt wax additive in 2012 [7] and Rotterdam (The Netherlands) announced a plan to produce recycled plastic segments in a factory for road construction in 2015 [8]. Moreover, Janshedpur (India) reported reducing bitumen usage by 7\% by mixing shredded recycled plastic during asphalt production [9]. More recently, a New Zealand asphalt contractor added shredded engine oil containers to asphalt at Christchurch Airport [10] and an independent asphalt producer includes recycled plastic as bitumen extended in every ton of asphalt produced. South Africa commenced recycled plastic trials in 2019, on a road near Jeffrey's Bay [11]. In Australia, a comparative trial of three recycled plastic extenders and modifiers was constructed in May 2018, which was shortly followed by trials in Melbourne [12], Sydney [13], Adelaide [14], and Canberra [15]. Previous use of recycled plastic in the United Kingdom has recently been expanded to include roads and highways from Cumbria in the north, to Kent in the South, and many counties in between [16]. Even the United States has now performed trials in San Diego [17] and, more recently, in downtown Los Angeles [18].

It is clear that there is great interest in the use of recycled plastic in bituminous binders and asphalt mixtures. It is also clear that different trials have taken very different approaches to using different kinds of plastic and this can only lead to confusion about the technology.

\subsection{Plastic Recycling in Asphalt Mixtures}

As stated above, there are many approaches to recycled plastic in asphalt mixtures. The polymer and form of plastic, the aim of the user and the local logistics will all influence the most appropriate approach to make. However, these same factors will also affect the properties of the resulting asphalt mixture and the long-term performance of the road surface. In general, there are four approaches to recycled plastic in asphalt mixtures:

- Uncontrolled waste disposal. Uncontrolled incorporation of variable plastic with only minimal processing to reduce the particle size to be comparable to asphalt mixture aggregates. This offers minimal return on the investment and a higher performance risk.

- Aggregate extension. Hard plastic does not melt at typical asphalt production temperatures but can partially replace or extend the aggregate in the mixture. However, the aggregate is much less expensive than the bituminous binder, so this approach provides a lower return on the investment. Some performance enhancement is often reported due to the reinforcing nature of the plastic, which is often flexible in nature.

- Binder extension. Soft plastic can be melted into the bituminous binder to partially replace or extend the binder without necessarily enhancing its properties. This provides a greater return on the investment than aggregate extension because the binder is significantly more expensive than the aggregate. 
- Binder extension and modification. When soft plastic is used to modify, as well as extend, the bituminous binder, the effects can be similar to those associated with traditional polymers for binder and mixture modification [19].

The use of plastics that can both modify and extend the bituminous binder is the most beneficial approach to recycling plastic is asphalt mixtures. This is because the extended bituminous binder is expensive, but the polymers that would otherwise be used for asphalt mixture performance enhancement are even more expensive.

\subsection{The Products}

Both MR6 and MR10 are developed and produced by MacRebur Ltd. [20]. In 2015, MR6 was developed to:

- $\quad$ Productively consume a portion of waste plastic otherwise destined for landfill.

- $\quad$ Reduce the cost of new road construction and maintenance.

- Increase the strength and durability of local roads.

MR6 was developed to improve deformation resistance via an increase in asphalt mixture stiffness. MR10 was developed to produce a more elastomeric and crack resistant bituminous binder. Both products are manufactured from $100 \%$ recycled plastic that was selected for its physical properties, as well as being otherwise not economically recyclable. That is, the plastic used to produce MR6 and MR10 would otherwise be disposed of in landfill because there are no viable alternate recycling opportunities at this time.

The original MR6, was developed in a pelletized form. This included melting, extruding, and cutting of the recycled plastic. This produced dense pellets with homogenous color (Figure 1). The density of the pellets was determined to optimize the international shipping costs, which are based on the worse case of product volume and weight. By adjusting the packed density, the volume-based and weight-based shipping costs were equal, which is the most efficient for shipping. MR10 was also developed as a pellet (Figure 1). However, to improve the distribution of MR6 through the asphalt mixture when a dry-mixing process is used, MR6 was converted to a shredded form in 2019. Due to the different chemical composition of MR10, it is still produced in a pelletized form (Figure 2).

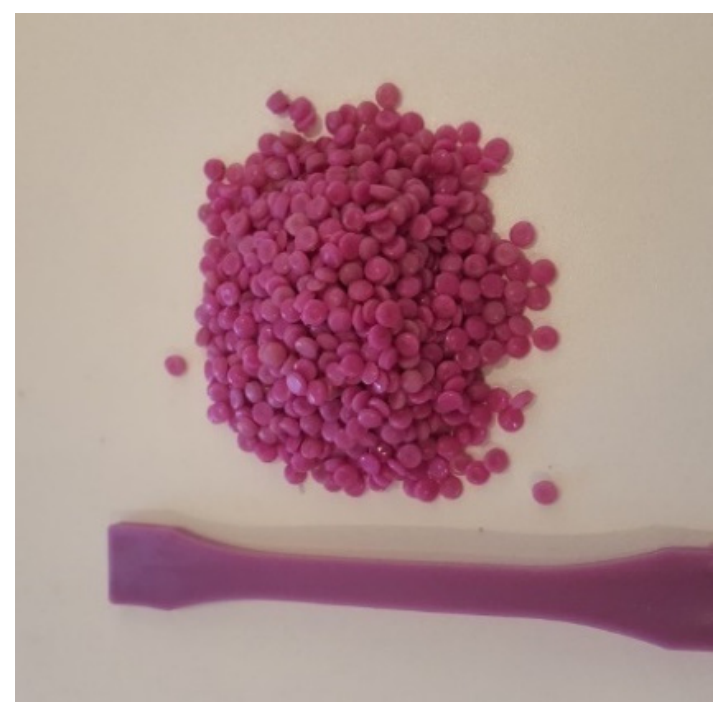

(a)

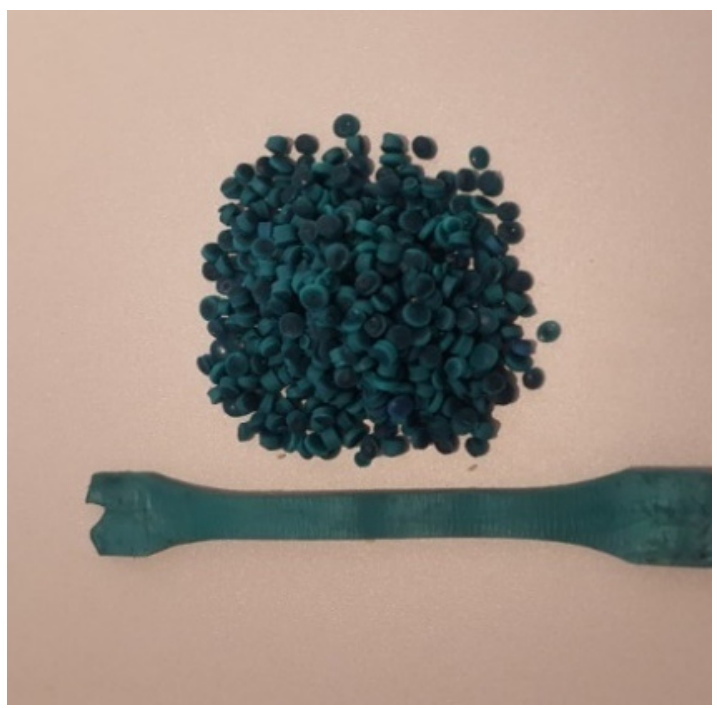

(b)

Figure 1. Original (a) MR6 pellets and (b) MR10 pellets. 


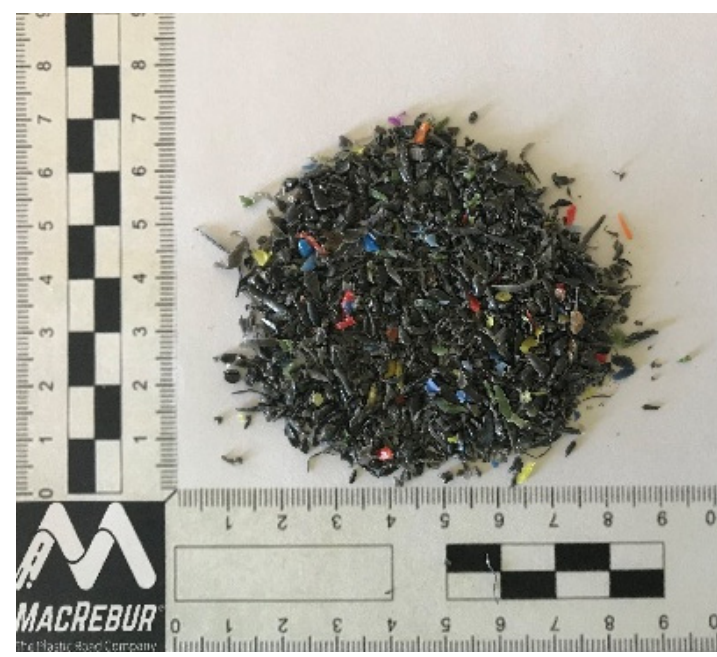

(a)

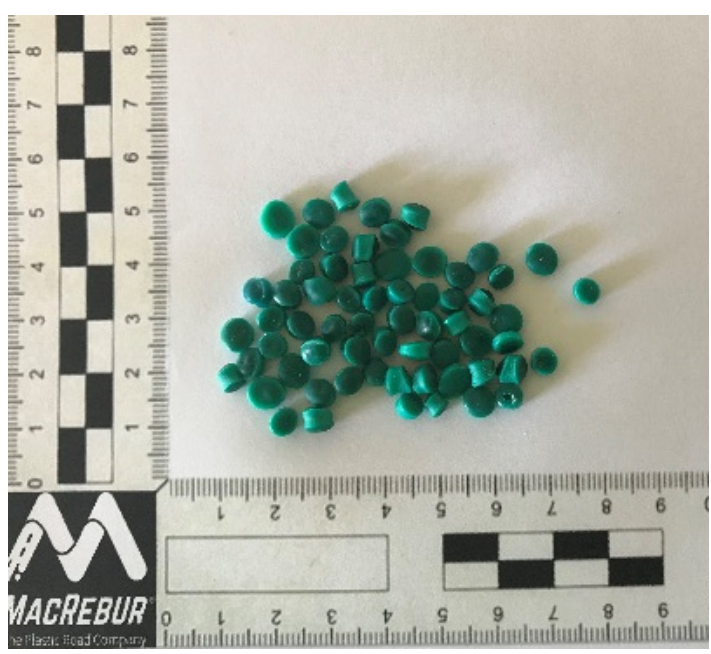

(b)

Figure 2. Current (a) MR6 shreddings and (b) MR10 (unchanged) pellets.

\section{Research Methods}

The data presented in this synthesis are extracted from existing publications on the effects of MR6 and MR10 on bituminous binder and asphalt mixture properties. The applicable publications are summarized in Table 1 . In all cases, the recycled plastic was added at a rate of $6 \%$ of the bituminous binder mass.

Table 1. MR6 and MR10 research publications.

\begin{tabular}{|c|c|c|c|}
\hline Title & Focus and Scope & Year & Reference \\
\hline $\begin{array}{l}\text { Recycled waste plastic for extending } \\
\text { and modifying asphalt binders }\end{array}$ & $\begin{array}{l}\text { Summary of the products and the } \\
\text { effect on asphalt mixture } \\
\text { performance properties }\end{array}$ & 2018 & [21] \\
\hline $\begin{array}{l}\text { Evaluating recycled waste plastic } \\
\text { modification and extension of } \\
\text { bituminous binder for asphalt }\end{array}$ & $\begin{array}{l}\text { The effect on typical asphalt mixture } \\
\text { performance properties, as well as } \\
\text { environmental and safety issues }\end{array}$ & 2019 & [22] \\
\hline $\begin{array}{l}\text { Recycled waste plastic modification of } \\
\text { bituminous binder }\end{array}$ & $\begin{array}{l}\text { The effect on the Performance Grade } \\
\text { (PG) rating of two penetration grade } \\
\text { bituminous binders }\end{array}$ & 2019 & [23] \\
\hline $\begin{array}{l}\text { Objective evaluation of the practical } \\
\text { benefits of asphalt binders modified } \\
\text { with recycled plastic }\end{array}$ & $\begin{array}{l}\text { The improvement in base and } \\
\text { surface mixture modulus and } \\
\text { fatigue life and the associated effect } \\
\text { on predicted pavement life }\end{array}$ & 2019 & [24] \\
\hline $\begin{array}{l}\text { Laboratory evaluation of asphalt } \\
\text { containing recycled plastic as a } \\
\text { bitumen extender and modifier }\end{array}$ & $\begin{array}{l}\text { Effect of common bituminous } \\
\text { binder properties and surface } \\
\text { mixture performance properties }\end{array}$ & 2019 & [25] \\
\hline $\begin{array}{l}\text { Comparing wet mixed and dry mixed } \\
\text { binder modification with recycled } \\
\text { waste plastic }\end{array}$ & $\begin{array}{l}\text { Comparison of the effect of wet and } \\
\text { dry production on bituminous } \\
\text { binder properties }\end{array}$ & 2020 & [26] \\
\hline $\begin{array}{l}\text { Recycled plastic as an alternative to } \\
\text { conventional polymers for } \\
\text { bituminous binder }\end{array}$ & $\begin{array}{l}\text { Summary of the effects on various } \\
\text { bituminous binder properties, } \\
\text { including those used in the UK, } \\
\text { Australia, and the USA }\end{array}$ & 2021 & {$[27]$} \\
\hline $\begin{array}{l}\text { Laboratory comparison of wet-mixing } \\
\text { and dry-mixing of recycled waste } \\
\text { plastic for binder and } \\
\text { asphalt modification }\end{array}$ & $\begin{array}{l}\text { Comparison of the effect of the } \\
\text { production process on the binder } \\
\text { and mixture properties of a } \\
\text { common surface mixture }\end{array}$ & 2021 & [28] \\
\hline
\end{tabular}


The general approach taken in the various research efforts detailed in Table 1 was to test otherwise nominally identical samples of bituminous binder and/or asphalt mixtures, produced with and without recycled plastic. The binder and mixture samples were typical of materials used for local and highway road construction in the United Kingdom and Australia. The binders were either viscosity (in Australia) or penetration (in the United Kingdom) grade materials, while the asphalt mixtures were either dense graded asphalt (DGA) or stone mastic asphalt (SMA) of various nominal maximum aggregate size (NMAS) (Table 2).

Table 2. Asphalt mixture properties.

\begin{tabular}{ccccc}
\hline \multirow{2}{*}{ Property } & \multicolumn{4}{c}{ Used by Research References } \\
\cline { 2 - 5 } & {$[21,24]$} & {$[21,22,24]$} & {$[25]$} & {$[26,28]$} \\
\hline Mixture type & Dense graded & Stone mastic & Dense graded & Dense graded \\
\hline NMAS $(\mathrm{mm})$ & 20 & 10 & 10 & 10 \\
\hline Binder content $(\%)$ & 4.8 & 6.3 & 4.9 & 5.2 \\
\hline Standard & EN 13108-1 & EN 13108-5 & BCC Type 3 & EN 13108-1 \\
\hline
\end{tabular}

The test methods were all standard methods used in the United Kingdom, the United States, and Australia for measuring the characteristics and relative performance of binders and mixtures, as summarized in Table 3, for bituminous binders, and Table 4, for asphalt mixtures.

Table 3. Bituminous binder test methods.

\begin{tabular}{cccc}
\hline Property & Method & Description & Measured in Research \\
\hline Penetration & EN 1426 & $\begin{array}{c}\text { Penetration by a standard } \\
\text { needle, over } 5 \text { s, into a binder } \\
\text { sample at } 25^{\circ} \mathrm{C}\end{array}$ & {$[23,26,28]$} \\
\hline Force ductility & EN 13703 & $\begin{array}{c}\text { Percentage of elongation until } \\
\text { separation of a binder sample at } \\
25{ }^{\circ} \mathrm{C}\end{array}$ & {$[23]$} \\
\hline Elastic recovery & EN 13398 & $\begin{array}{c}\text { Percentage recovery of a cut } \\
\text { binder sample after elongation } \\
\text { by } 200 \text { mm at } 25^{\circ} \mathrm{C}\end{array}$ & {$[26,28]$} \\
\hline Softening point & EN 1427 (UK) and & $\begin{array}{c}\text { Softening temperature of a } \\
\text { binder sample according to the } \\
\text { Ring and Ball method }\end{array}$ & {$[23,25,26,28]$} \\
\hline AG:PT/T131 (A) & AS 2341.2 & $\begin{array}{c}\text { Propensity of the binder to flow } \\
\text { under load at } 60^{\circ} \mathrm{C}\end{array}$ & {$[25]$} \\
\hline $\begin{array}{l}\text { Torsional } \\
\text { recovery }\end{array}$ & AG:PT/T122 & $\begin{array}{c}\text { Percentage of torsional recovery } \\
\text { of a binder sample after rotating } \\
180^{\circ} \text { at } 25^{\circ} \mathrm{C}\end{array}$ & {$[25]$} \\
\hline
\end{tabular}

(UK) denotes the method used in the UK while (A) denotes the test method used in Australia.

Table 4. Asphalt test methods.

\begin{tabular}{cccc}
\hline Property & Method & Description & Measured in Research \\
\hline Stiffness & EN 12697-26 (UK) AS & $\begin{array}{c}\text { Indirect tensile modulus at } 20^{\circ} \mathrm{C} \\
\text { (UK) or 25 }{ }^{\circ} \mathrm{C}(\mathrm{A}) \text {, an indicator of } \\
\text { sample stiffness }\end{array}$ & {$[22,24,25]$} \\
Stiffness & EN 12697-34 (UK) & $\begin{array}{c}\text { Marshall Stability of samples } \\
\text { prepared by } 50 \text { blows to each side } \\
\text { by a standard Marshall hammer and } \\
\text { tested at } 60^{\circ} \mathrm{C}\end{array}$ & {$[25,26,28]$} \\
\hline
\end{tabular}


Table 4. Cont.

\begin{tabular}{|c|c|c|c|}
\hline Property & Method & Description & Measured in Research \\
\hline Deformation resistance & $\begin{array}{c}\text { EN 12697-22 (UK) } \\
\text { AG:PT/T231 (A) }\end{array}$ & $\begin{array}{c}\text { Deformation following } 10,000 \\
\text { passes of a Cooper's wheel tracking } \\
\text { wheel of samples at a } \\
\text { pre-determined temperature, } \\
\text { generally } 40-60^{\circ} \mathrm{C}\end{array}$ & {$[21,22,25,26,28]$} \\
\hline Cracking resistance & EN 12697-24 & $\begin{array}{l}\text { Indirect tensile fatigue life of over a } \\
\text { range of initial tensile strain } \\
\text { magnitudes to develop a } \\
\text { relationship between initial strain } \\
\text { and cycles to failure, an indicator of } \\
\text { sample fatigue life }\end{array}$ & {$[22,24,26,28]$} \\
\hline Cracking resistance & AG:PT/T274 & $\begin{array}{l}\text { Four-point bending at } 20^{\circ} \mathrm{C} \text { and } 200 \\
\mu \varepsilon \text { sinusoidal repeated load, an } \\
\text { indicator of sample fatigue life }\end{array}$ & [25] \\
\hline Cracking resistance & EN 12697-44 & $\begin{array}{l}\text { Semicircular bending of notched } \\
\text { samples under monotonic loading } \\
\text { and tested at } 0{ }^{\circ} \mathrm{C} \text {, an indicator of } \\
\text { sample fracture toughness }\end{array}$ & {$[21,22]$} \\
\hline Cracking resistance & $\begin{array}{r}\text { EN 12697-34 (UK) } \\
\text { AS/NZS 2891.5 (A) }\end{array}$ & $\begin{array}{c}\text { Marshall Flow of samples prepared } \\
\text { by } 50 \text { blows to each side by a } \\
\text { standard Marshall hammer and } \\
\text { tested at } 60^{\circ} \mathrm{C}\end{array}$ & {$[25,26,28]$} \\
\hline $\begin{array}{l}\text { Moisture damage } \\
\text { resistance }\end{array}$ & $\begin{array}{l}\text { EN 12697-12 (UK) } \\
\text { AG:PT/T232 (A) }\end{array}$ & $\begin{array}{l}\text { Ratio of indirect tensile strength of } \\
\text { conditioned and unconditioned } \\
\text { samples, where conditioning } \\
\text { includes saturation and } 72 \mathrm{~h} \text { in } \\
40^{\circ} \mathrm{C} \text { water }\end{array}$ & {$[21,22,25,26,28]$} \\
\hline
\end{tabular}

(UK) denotes the method used in the UK, while (A) denotes the test method used in Australia.

\section{Effect on Bituminous Binders}

\subsection{Resistance to Flow}

Viscosity at $60^{\circ} \mathrm{C}$ measures flow potential, while penetration measures the resistance to flow. Generally, penetration and viscosity are inversely related, with viscosity increasing as penetration decreases for the same bituminous binder. The penetration of 100-150 penetration grade bitumen sourced and tested in the UK [23] reduced by 33\% and 30\%, with the addition of MR6 and MR10, respectively (Figure 3). Similarly, for 70-100 penetration bitumen, MR6 [26] and MR10 [28] reduced the penetration by $54 \%$ and $36 \%$, respectively (Figure 4 ). Accelerated laboratory aging by the rolling thin film over (RTFO) reduced the unmodified binder penetration from $100 \mathrm{~d} . \mathrm{mm}$ to $53 \mathrm{~d} . \mathrm{mm}$ and the penetration of the MR6 and MR10 modified samples was $45 \%$ and $32 \%$ of the unmodified binder penetration after RTFO (Figure 4). The reduced relative penetration after RTFO aging indicates that the addition of recycled plastic may also slow the binder aging process. However, specific studies are required to confirm this. Finally, the viscosity of Australian C170 (viscosity grade) bitumen [25] increased by $113 \%$ for MR6 and by $164 \%$ for MR10 (Figure 5).

All these results indicate the addition of recycled plastic to otherwise unmodified bitumen increases the resistance to flow of the bituminous binder. This is similar to the effect observed when conventional styrene-butadiene-styrene (SBS) and ethyl vinyl acetate (EVA) polymers are added to binders at comparable dosages. 


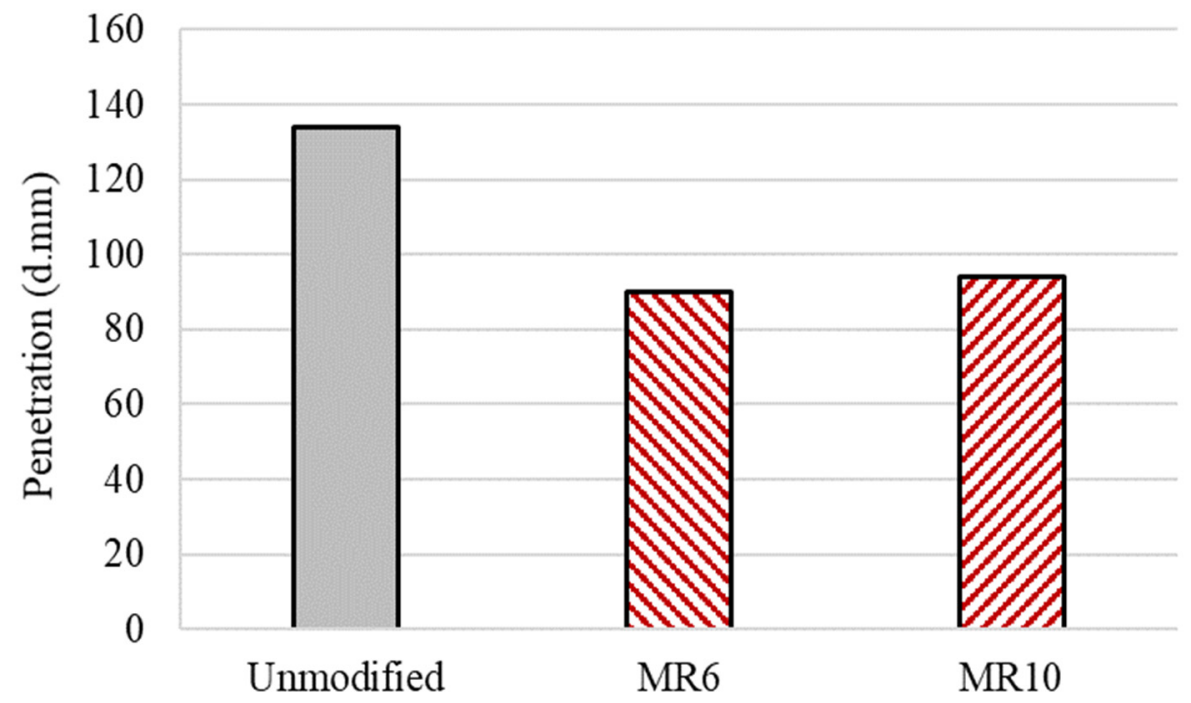

Figure 3. Effect of recycled plastic on 100-150 bitumen penetration [23].

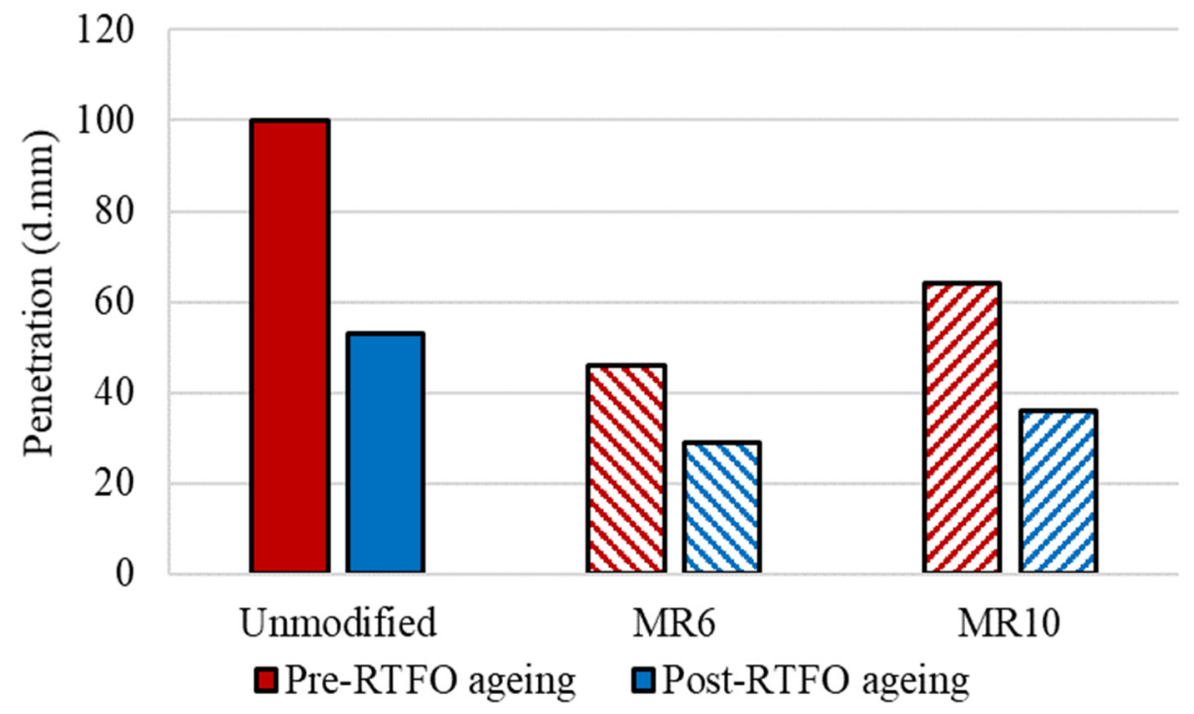

Figure 4. Effect of recycled plastic on unaged and aged 70-100 bitumen penetration [26,28].

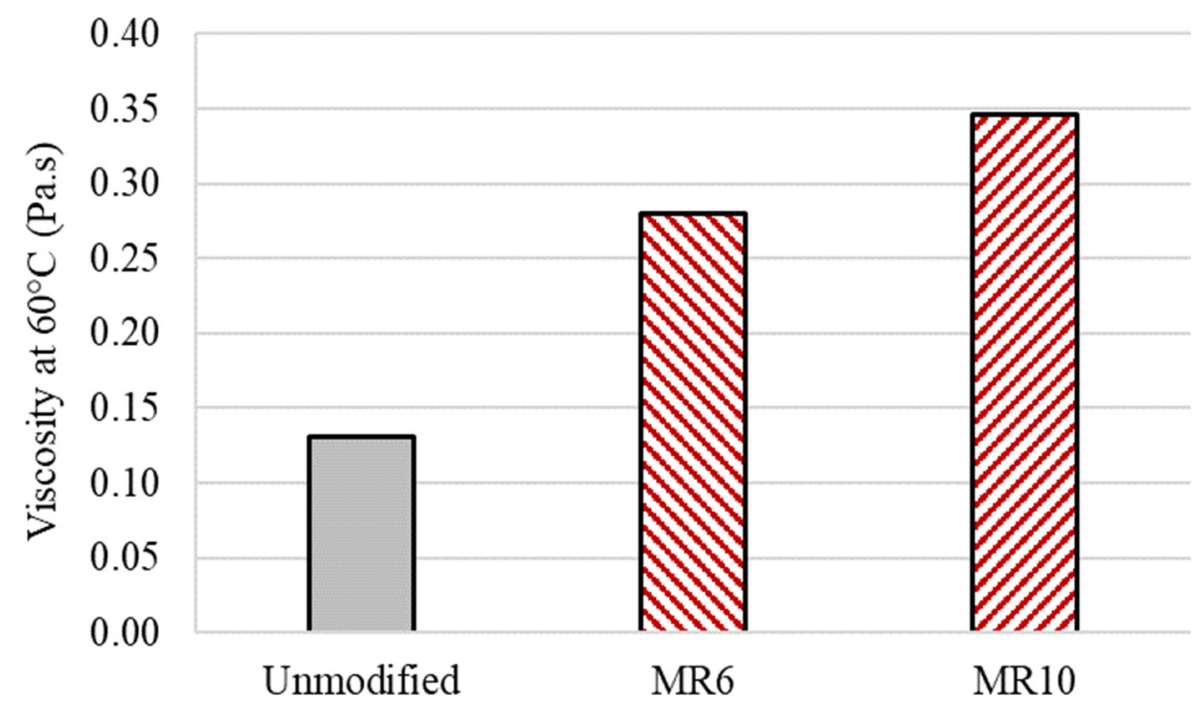

Figure 5. Effect of recycled plastic on C170 viscosity [25]. 


\subsection{Elasticity and Ductility}

Force ductility measures the degree of elongation before a bituminous binder sample is broken. Both torsional recovery and elastic recovery measure the degree to which a sample recovers after deforming, either by rotation or by elongation. Unmodified 100-150 penetration bitumen and C320 viscosity grade bitumen have negligible elasticity or ductility. However, when recycled plastic is added, the force ductility [25] (Figure 6), elastic recovery [26,28] (Figure 7), and torsional recovery [25] (Figure 8) all increased significantly. MR10 had a greater effect on the elasticity and ductility of the binder than MR6 did. The introduction of significant ductility and elasticity is consistent with the effect of moderate SBS or significant EVA conventional polymer modification of bituminous binder [19].

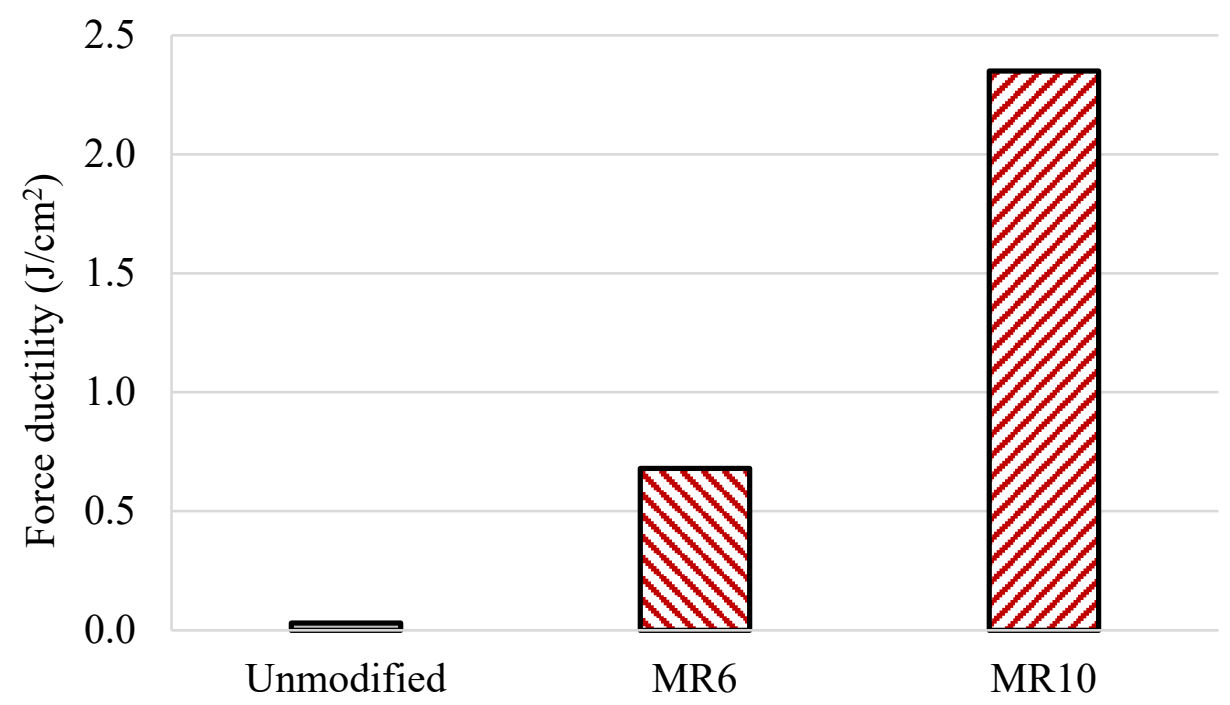

Figure 6. Effect of recycled plastic on 100-150 bitumen force ductility [23].

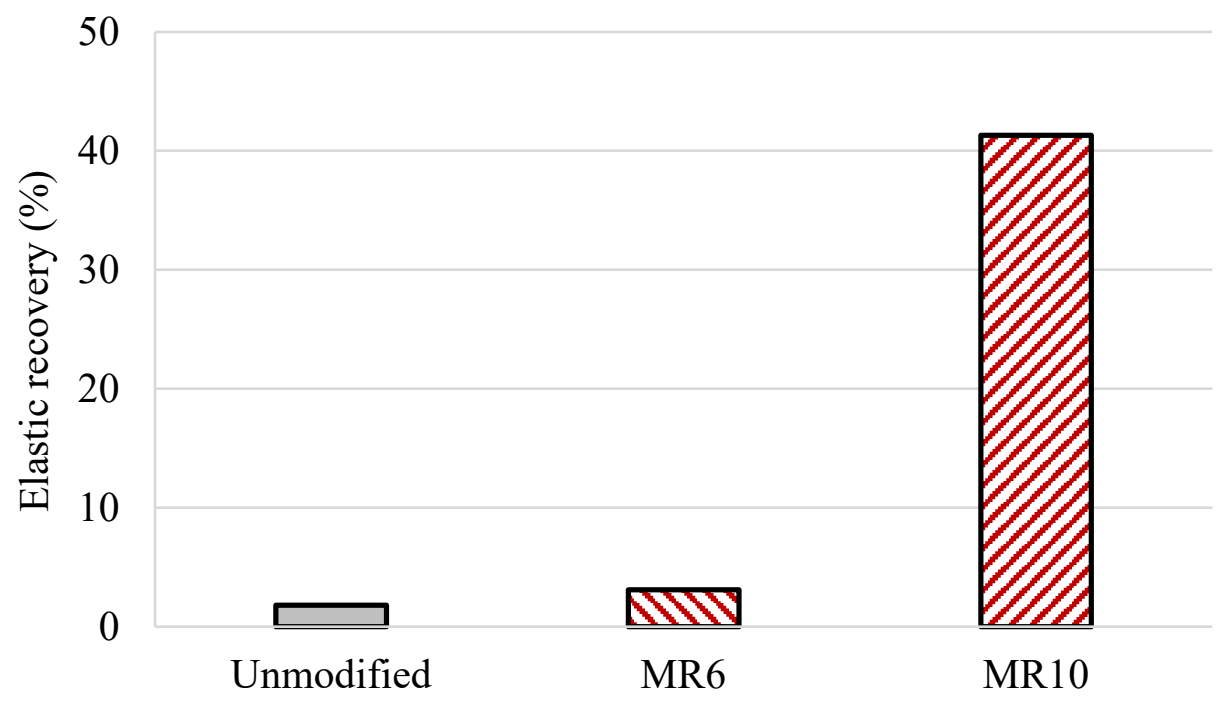

Figure 7. Effect of recycled plastic on 70-100 bitumen elastic recovery [26,28]. 


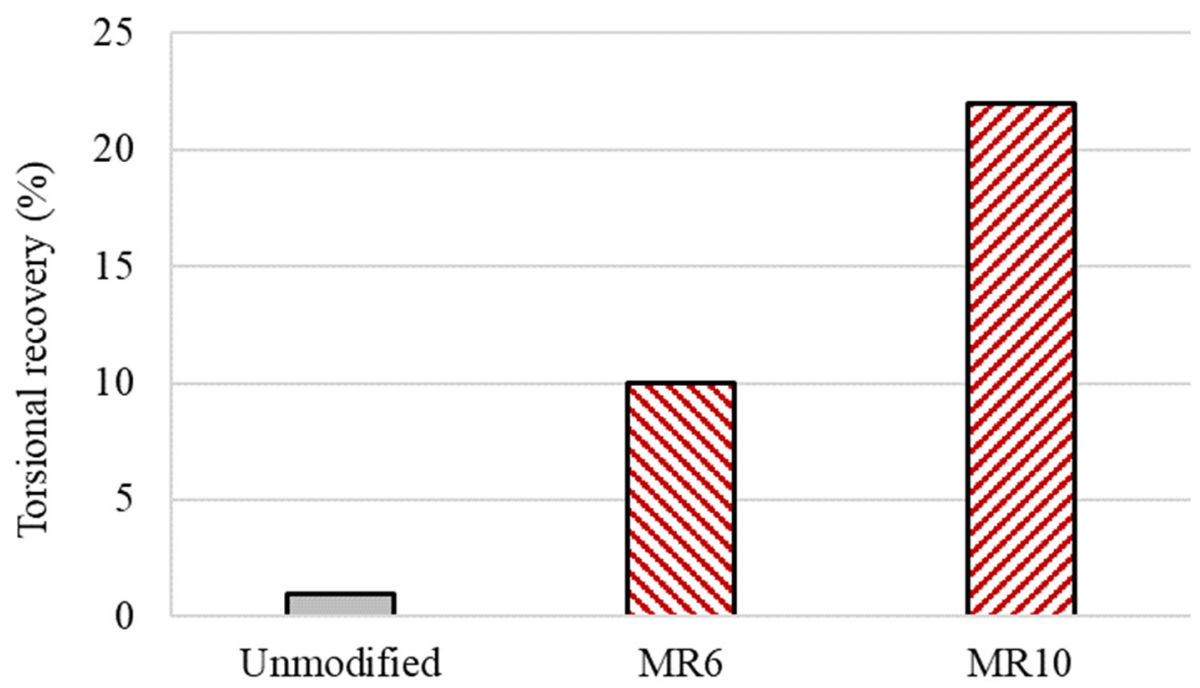

Figure 8. Effect of recycled plastic on C170 torsional recovery [25].

\subsection{Temperature Susceptibility}

Softening point is a globally recognized index property for indicating the temperature susceptibility of polymer modified binders. In general, a bituminous binder with a higher penetration will have a lower softening point. When recycled plastic was added to 100-150 penetration grade bitumen in the UK, the softening point increased by $22 \%$ (MR6) and 14\% (MR10) [23]. For Australian C170 bitumen, the softening point increased by $45 \%$ and $32 \%$, for MR6 and MR10, respectively [25]. Finally, the softening point of $70-100$ penetration binder increased by $40 \%$ and $20 \%$, with the addition of MR6 [26] and MR10 [28], respectively. The RTFO aging of the binder increased the softening point by $16 \%$, reflecting the oxidative hardening of the bitumen. After RTFO, the effect of recycled plastic was reduced, with a $27 \%$ and $22 \%$ increase associated with MR6 and MR10, respectively. This again indicates that recycled plastic may reduce the rate of aging of binders.

Because the softening point test protocol is almost identical in Australia and the UK, the average effect was examined by combining the various data sets (Figure 9). Overall, the addition of MR6 increased the binder softening point by $33 \%$, while the addition of MR10 increased the softening point by an average of $23 \%$, and the effect of both was significant ( $p$-values 0.01 and 0.02 , respectively).

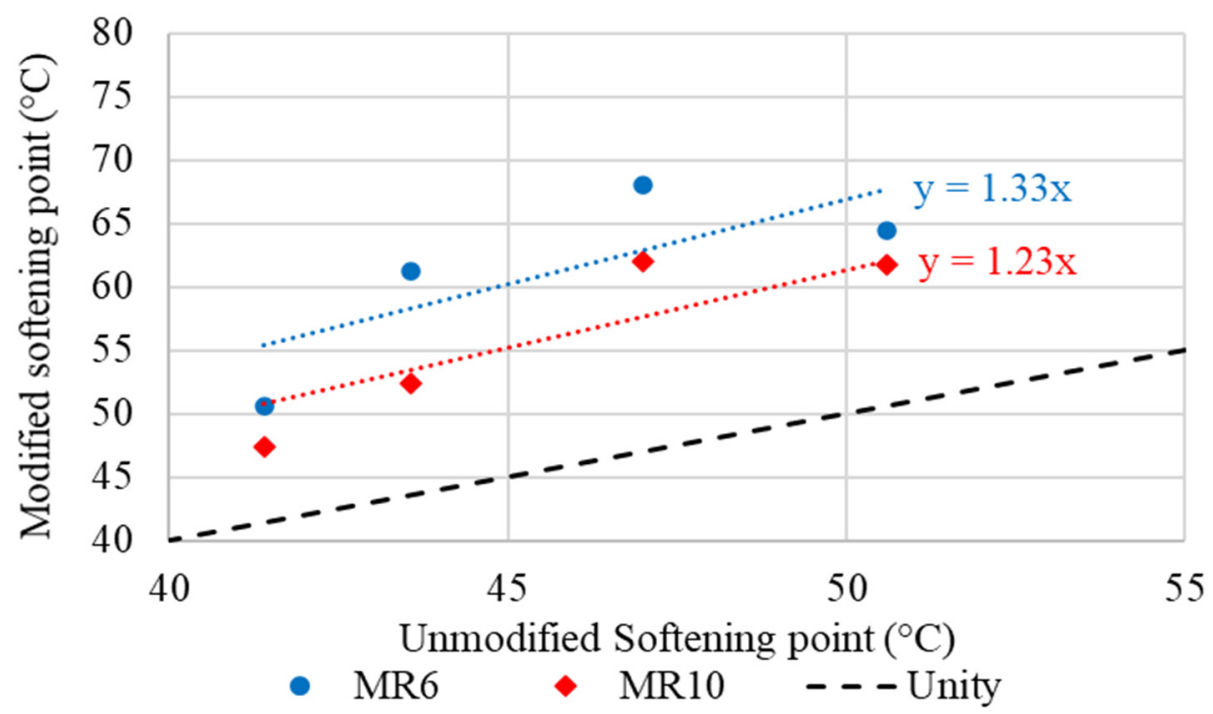

Figure 9. Effect of recycled plastic on binder softening point $[23,25,26,28]$. 


\subsection{Performance Grading}

The PG rating and specification of bituminous binders in the USA were the result of the Superpave project conducted in the 1990s [29]. Although there are also low-temperature parameters, the primary parameter of interest is the high-temperature limit. The original PG grading was based on the DSR parameter known as $\mathrm{G}^{*} / \sin (\delta)$. However, since 2011, the DSR protocol known as the multiple stress creep recovery (MSCR) has been used to measure the parameter known as Jnr(3.2), which provides a best-practice basis of high-temperature PG rating [30].

Both a 100-150 and a 50-70 penetration grade bitumen from the UK were modified with MR6 and MR10 [23]. Both MR6 and MR10 increased the PG of both bitumens significantly (Figure 10). On average, MR6 was associated with four grade increases, while MR10 was associated with an average of three grade increases (Figure 11). Three to four PG rating increases under the MSCR-based PG system is comparable to the effect of conventional SBS and EVA polymers for bituminous binder modification [31].

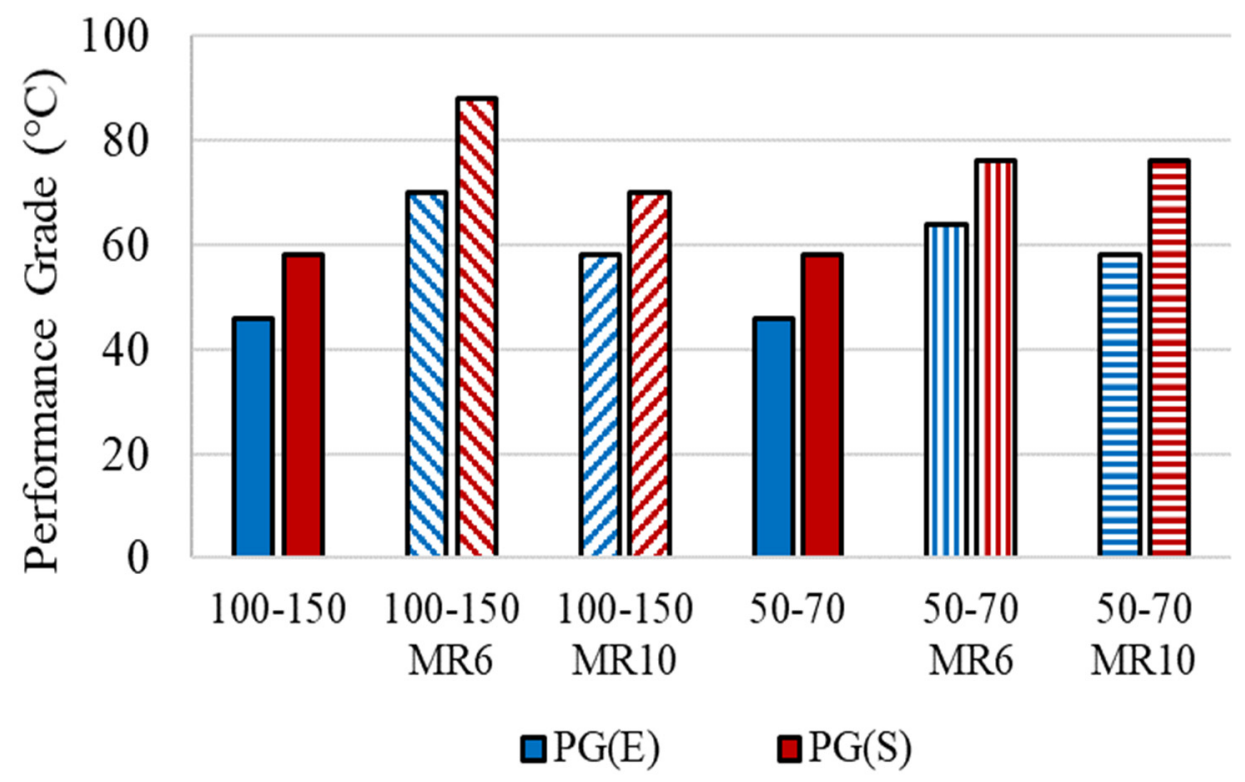

Figure 10. Effect of recycled plastic on binder multiple stress creep recovery (MSCR PG) rating [23].

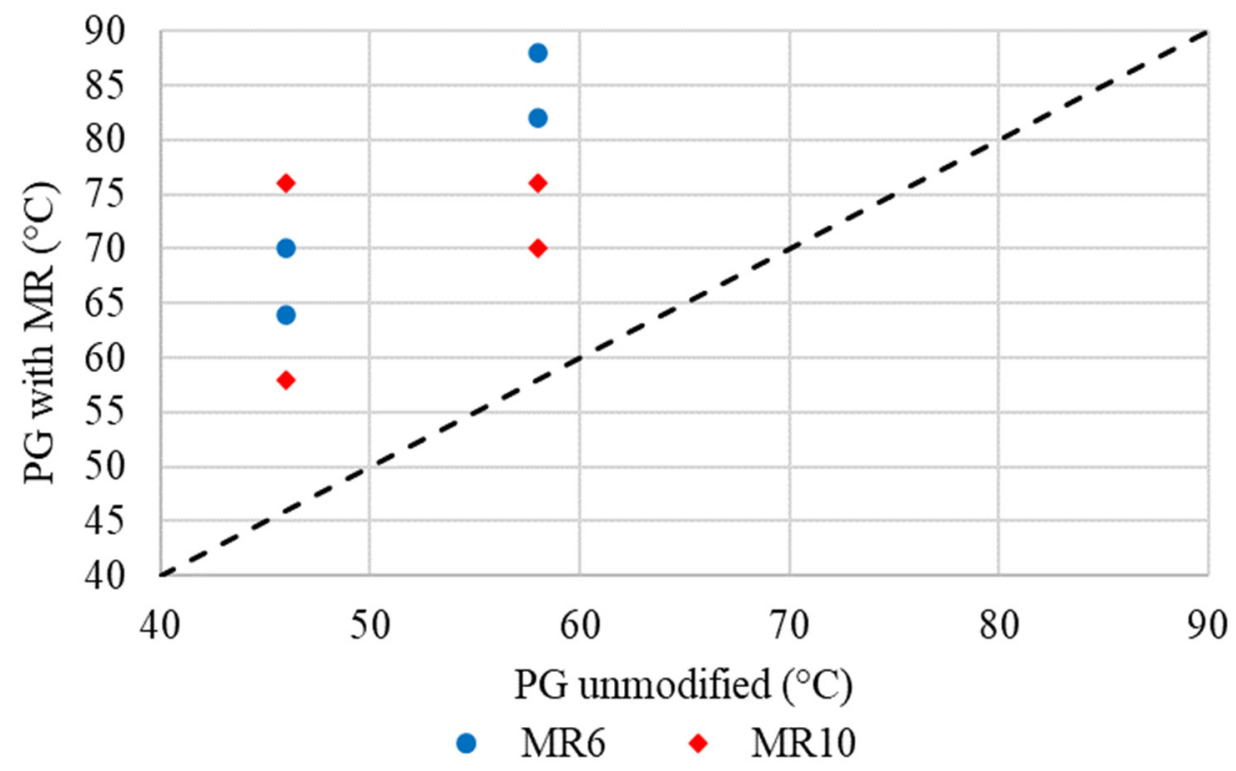

Figure 11. PG increase for recycled plastic modified binders [23]. 


\section{Effect on Asphalt Mixtures}

\subsection{Stiffness}

The stiffness, or modulus, of asphalt mixtures is used as a relative indicator of the structural contribution of the layer to the strength of the pavement. Modulus is the only parameter routinely measured on asphalt mixtures that is then directly related to pavement thickness design. The stiffer the asphalt mixture, the stronger the pavement will be, or the thinner the pavement can be without compromising its load-carrying ability. Although not a direct measure of the stiffness, the Marshall Stability is generally accepted as an indicator of the bituminous binder's contribution to asphalt mixture stiffness when the composition of the asphalt mixture is otherwise kept constant.

A typical UK DGA with NMAS of $20 \mathrm{~mm}$, referred to as DGA 20, was produced with and without recycled plastic modified asphalt binder [21]. In the same research, an SMA with a 10 mm NMAS, referred to as SMA 10, was produced with and without recycled plastic modified asphalt binder [21]. In both cases, the base asphalt was the typical UK 40-60 penetration grade. The MR6 increased the DGA 20 modulus by $48 \%$, whereas the SMA 10 modulus increased by $198 \%$ (for MR6) and 254\% (for MR10), as shown in Figure 12.

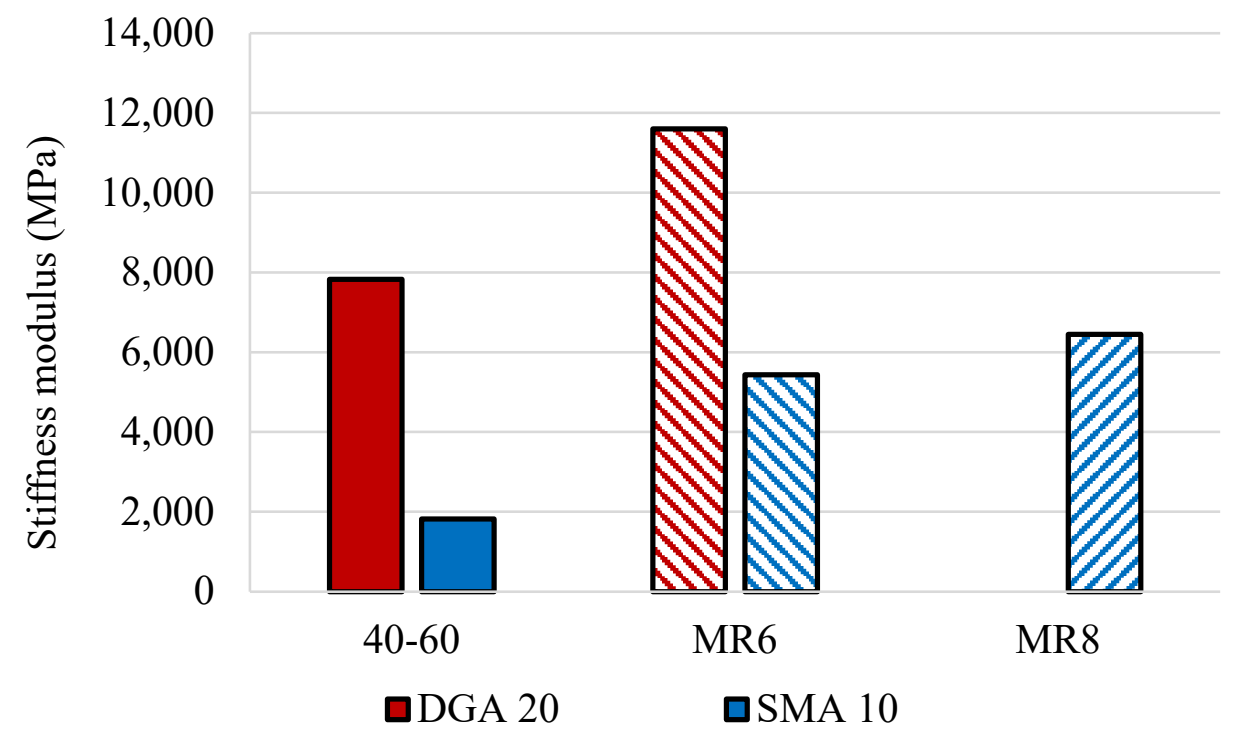

Figure 12. Stiffness modulus increase for UK DGA 20 and SMA 10 [21].

In related work [26,28], a comparison of wet-mixing and dry-mixing of recycled plastic in otherwise nominally identical $10 \mathrm{~mm}$ NMAS DGA in the UK, referred to as DGA 10, significantly increased the Marshall Stability for the recycled plastic modified asphalt mixture (Figure 13). The stiffness increase was $80 \%-83 \%$ (for MR6) and 110\%-161\% (for MR10) and the effect of the recycled plastic (plastic modified versus unmodified 50-70) and recycled plastic type (MR6 versus MR10) was more significant than the effect of the production process (wet-mixing versus dry-mixing). 


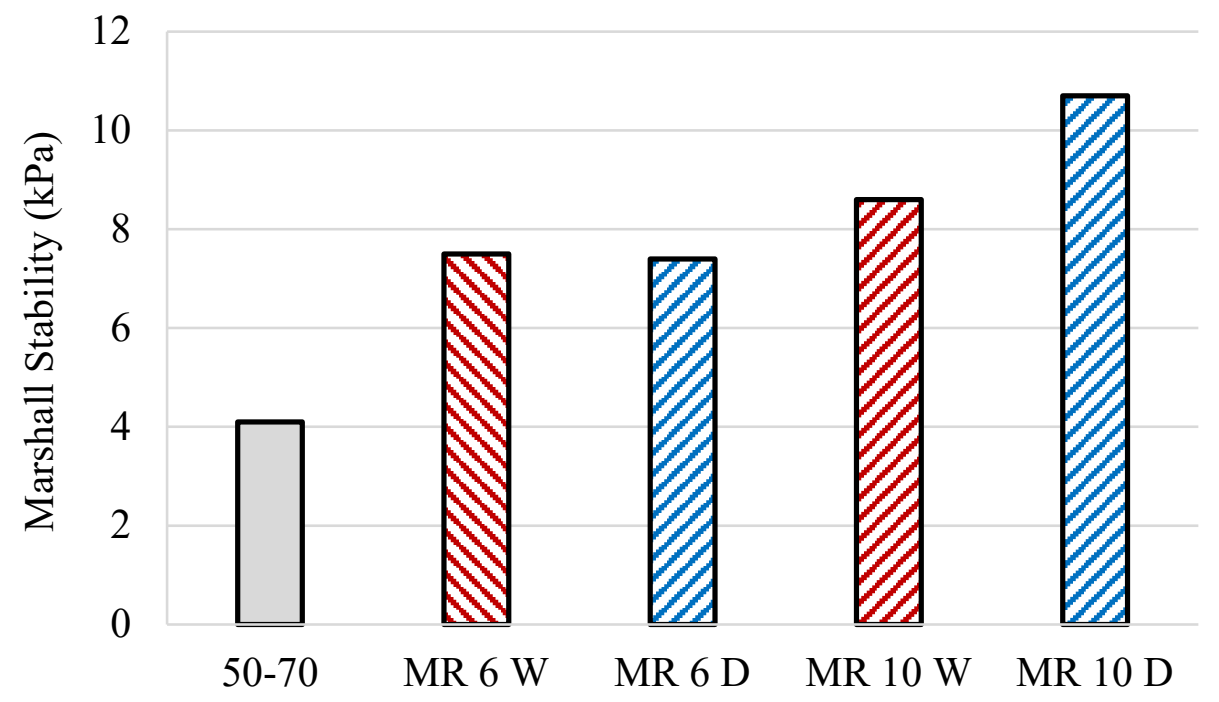

Figure 13. Marshall Stability increase for UK DGA 10 [26,28]. W = Wet mixed and D = Dry mixed.

In similar research on a typical DGA road surface mixture produced to Australian specifications, referred to as DGA 10, the effect of recycled plastic modified binder was compared to unmodified viscosity grade (C320) bitumen with quadruplicate samples [25]. The recycled plastic increased the asphalt mixture resilient modulus by $12 \%$ (for MR6) and $8 \%$ (for MR10), as shown in Figure 14. The increase in stiffness was significant, with $p$-values of 0.01 and $<0.01$, for MR6 and MR10, respectively. In the same work, the recycled plastic modified asphalt binder produced mixtures with a $32 \%$ (MR6) and $8 \%$ (MR10) higher Marshall Stability, compared to unmodified C320 asphalt (Figure 15). Again, the increase was significant, with $p$-values $<0.01$ and 0.04 , for MR6 and MR10, respectively.

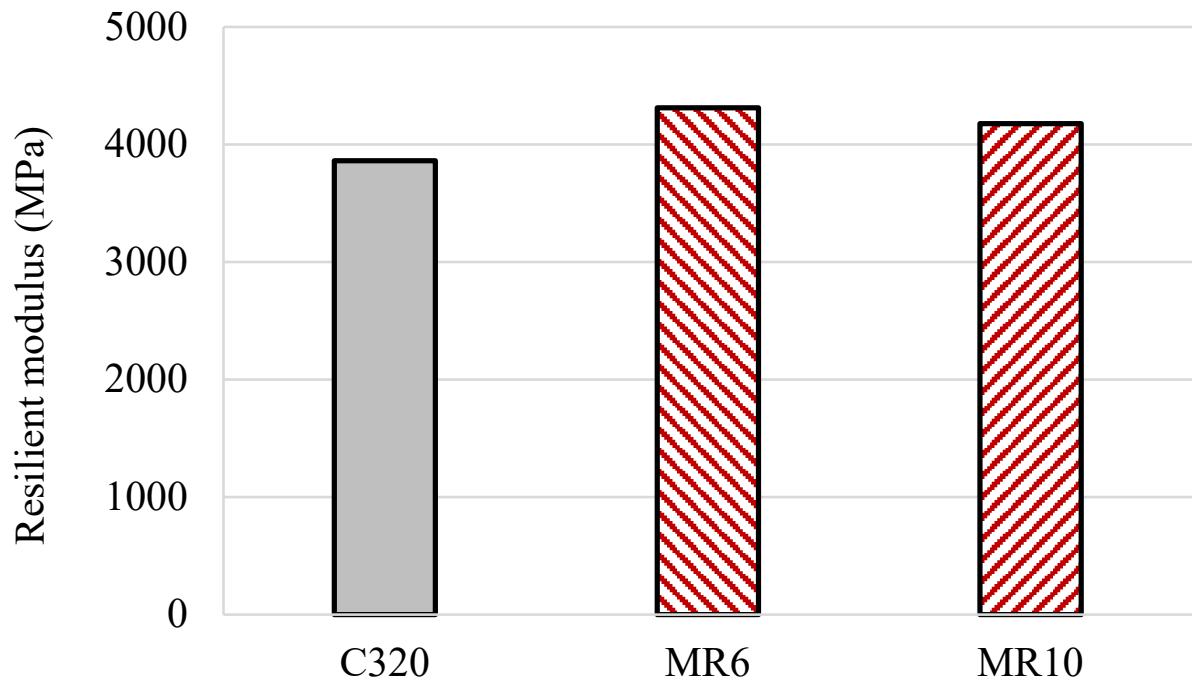

Figure 14. Resilient modulus increase for Australian DGA 10 [25]. 


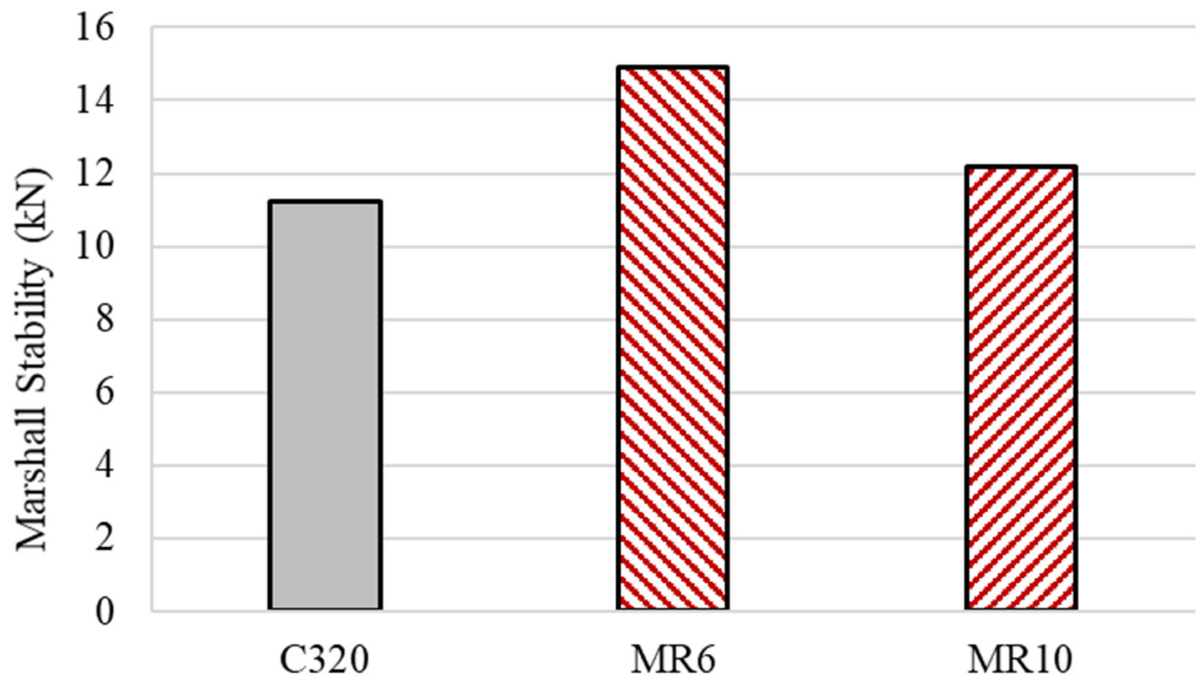

Figure 15. Marshall Stability increase for Australian DGA 10 [25].

The results of SMA and DGA mixture testing, for samples produced with unmodified asphalt and asphalt binder modified with recycled plastic, generally indicate a consistent and significant increase in the stiffness associated with MR6 and MR10 recycled plastic. This is consistent with the effect of conventional polymer modification, particularly for the plastomeric polymer EVA [19].

\subsection{Deformation Resistance}

Deformation resistance is measured in the UK and Australia using the Copper's wheel tracking machine and is a well-established indirect measure of asphalt mixture resistance to rutting, shoving, and shearing. Other countries, such as the USA, use different wheel tracking equipment or more fundamental deformation resistance tests, such as Flow Number/Time [32].

The Copper's wheel tracking test was performed on otherwise nominally identical asphalt mixtures produced with and without recycled plastic modified binders in both the UK and Australia. This included UK DGA 20 and SMA 10 [21], UK DGA 10 [26,28], and Australian DGA 10 [25]. On average, MR6 was associated with a 65\% reduction in the final wheel tracking depth, whereas MR10 was associated with a $43 \%$ reduction (Figure 16). The average reduction was statistically significant for both recycled plastic products ( $p$-values $<0.01$ ). This significant increase in asphalt mixture deformation resistance is comparable to that associated with conventional polymers for asphalt binder modification, such as SBS and EVA [19].

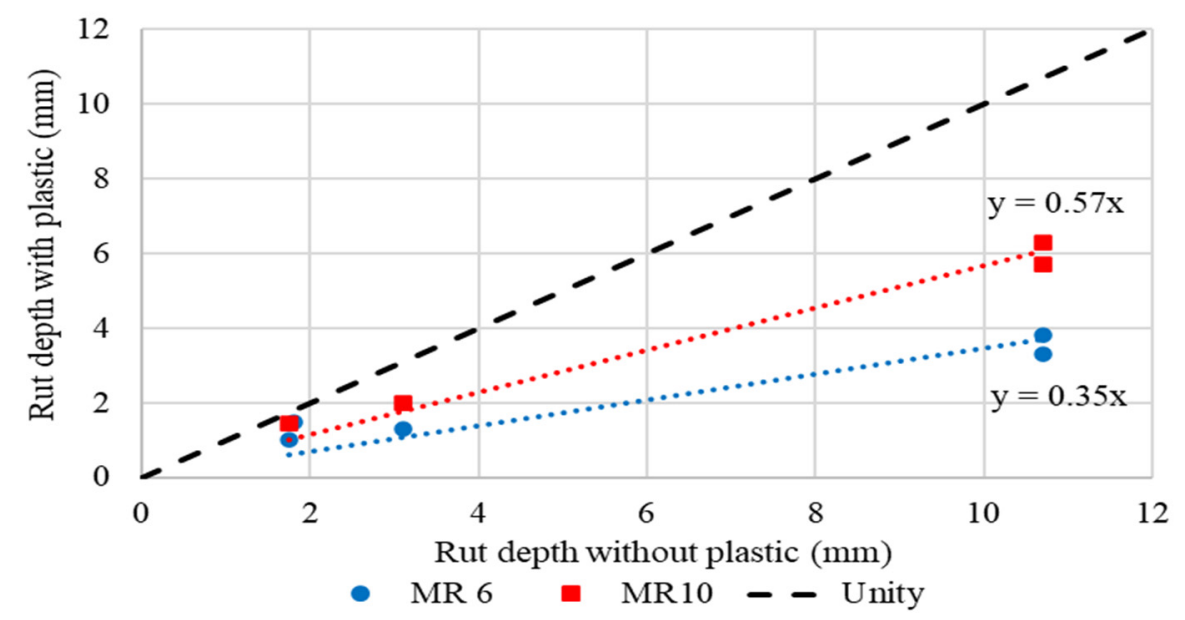

Figure 16. Effect of recycled plastic on mixture wheel tracking depth $[21,25,26,28]$. 


\subsection{Cracking Resistance}

Cracking resistance is a combination of the resistance to crack initiation (fatigue resistance) as well as resistance to subsequent crack propagation (fracture resistance). There are many laboratory tests for asphalt mixture resistance to cracking, with fatigue tests usually using a cyclic load of a regular sample, while fracture tests usually use monotonic loading of a sample with a pre-made notch or crack initiation point. Although not a direct measure of fatigue of fracture resistance, the Marshall Flow test is generally accepted as an indicator of the asphalt binder's relative contribution to the crack resistance of an asphalt mixture when the mixtures are otherwise comparable.

The fracture toughness of a typical UK SMA 10 was measured for otherwise nominally identical mixtures, with and without recycled plastic modified asphalt binder [21]. The fracture toughness increased by $22 \%$ (for MR6) and $16 \%$ (for MR10), as shown in Figure 17. In similar work [22], mixture-specific fatigue life relationships were developed for the same nominal SMA 10 mixture, produced with and without recycled plastic, as well as for a typical UK DGA 20 mixture [24]. Over a practical range of induced strain magnitudes (100-500 $\mu \varepsilon)$, the fatigue life of the SMA 10 increased by an average 11\% (for MR6) and 8\% (for MR10), as shown in Figure 18. These improvements in average fatigue life increased to $52 \%$ and $46 \%$ for the DGA 20 mixture, for MR6 and MR10, respectively (Figure 19).

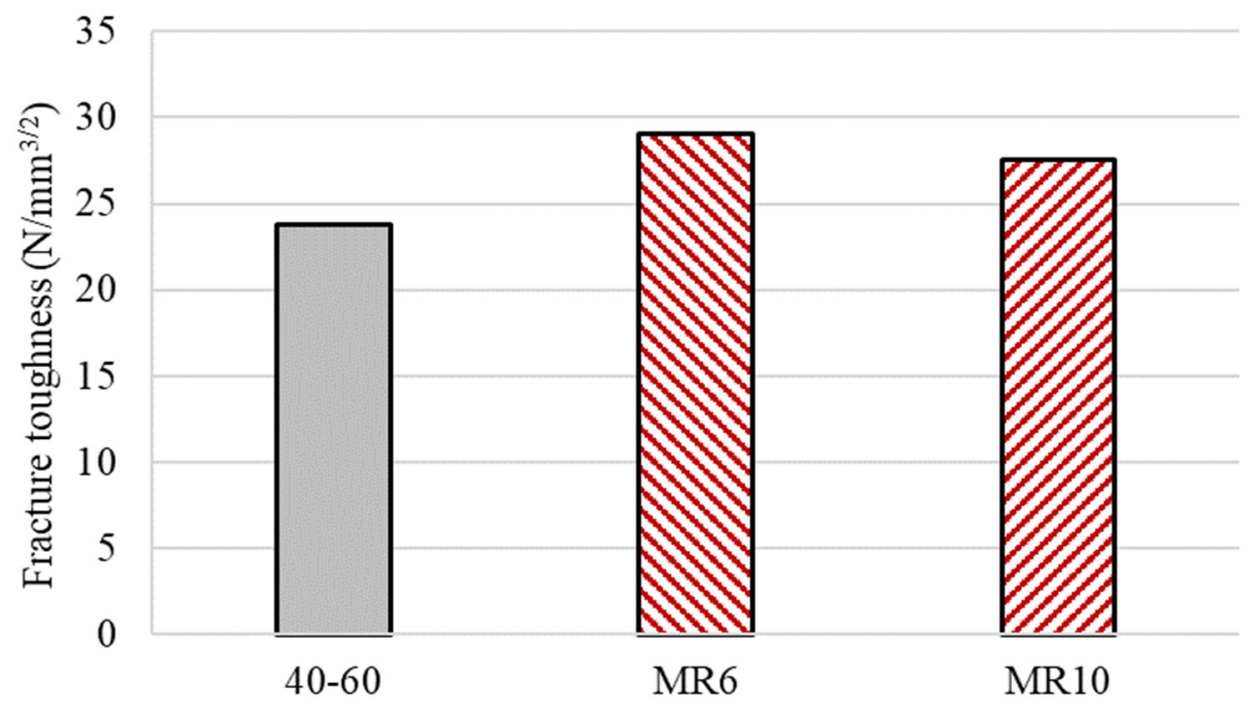

Figure 17. Effect of recycled plastic on SMA 10 fracture toughness [21].

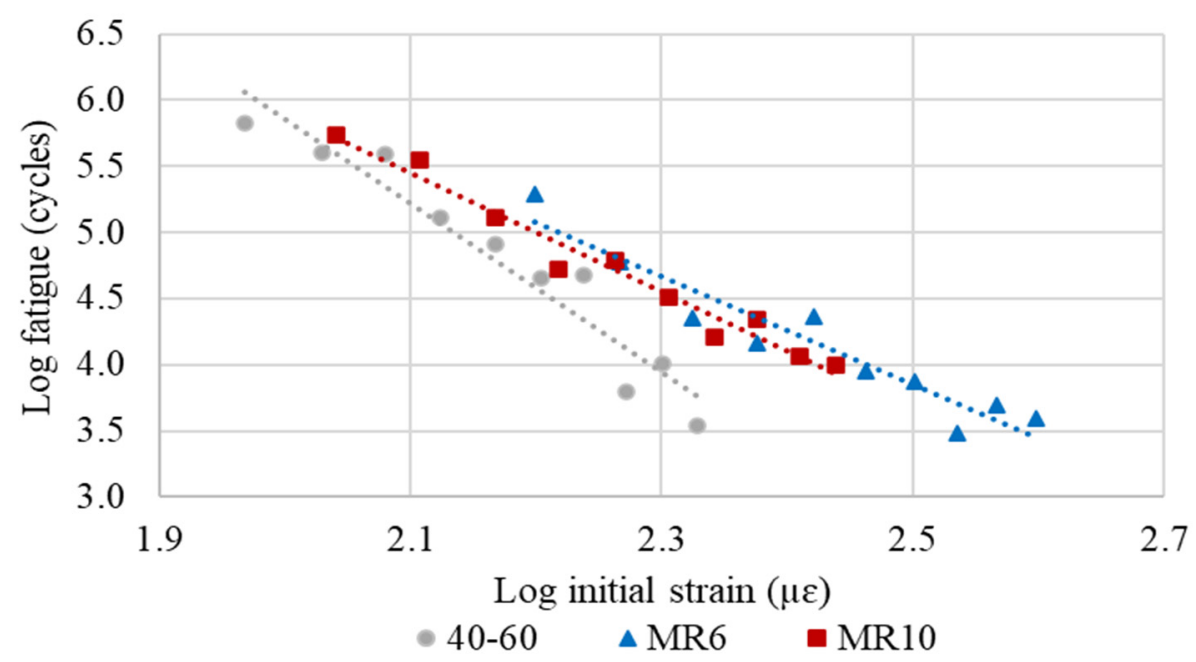

Figure 18. Effect of recycled plastic on SMA 10 fatigue life [22,24]. 


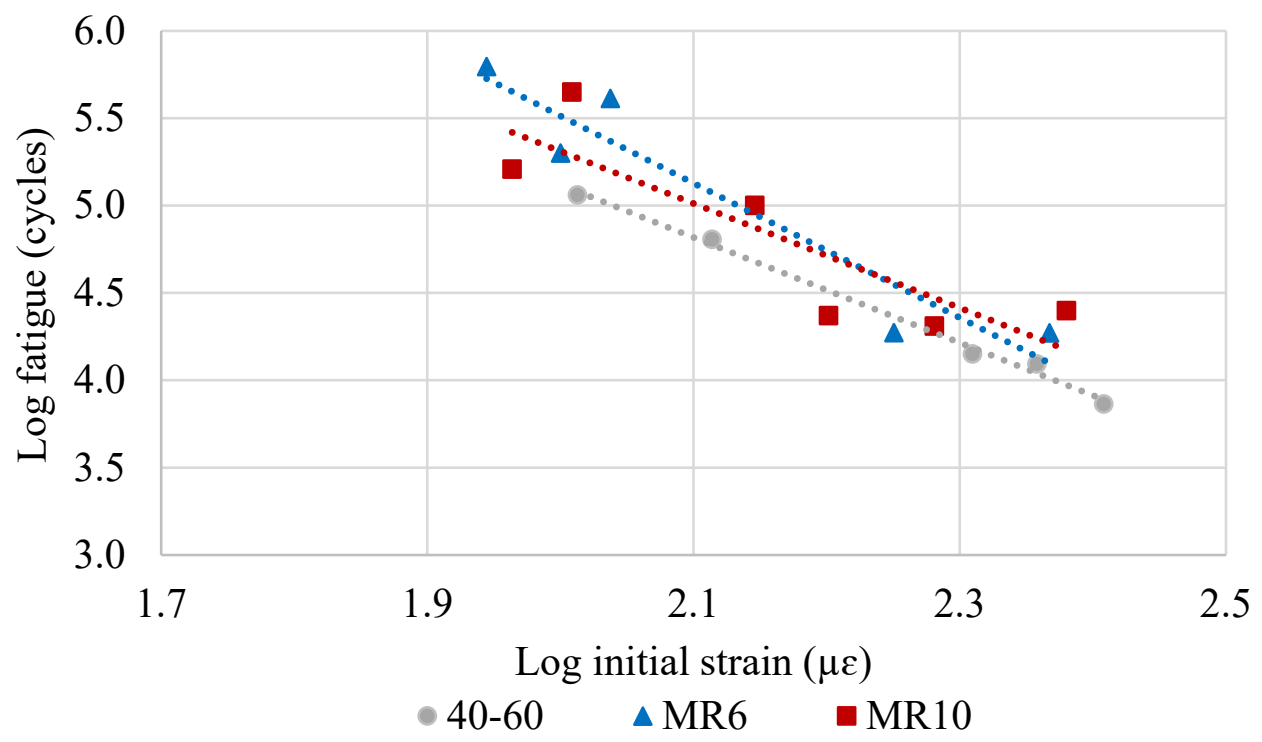

Figure 19. Effect of recycled plastic on DGA 20 fatigue life [22,24].

In similar work, the fatigue life of a typical UK DGA 10 was measured for otherwise nominally identical mixtures produced with unmodified 50-70 penetration asphalt, as well as with recycled plastic incorporated by dry-mixing and wet-mixing processes [28]. The fatigue life relationships were generally similar (Figure 20) and the associated fatigue life models were not significantly different ( $p$-values 0.33 to 0.74 ). Furthermore, the production method (wet-mixing versus dry-mixing) had no significant effect on the fatigue lives measured ( $p$-value 0.49 ). The same research also measured Marshall Flow and the results indicated only minor differences in the results associated with the unmodified and recycled plastic modified asphalt binders (Figure 21).

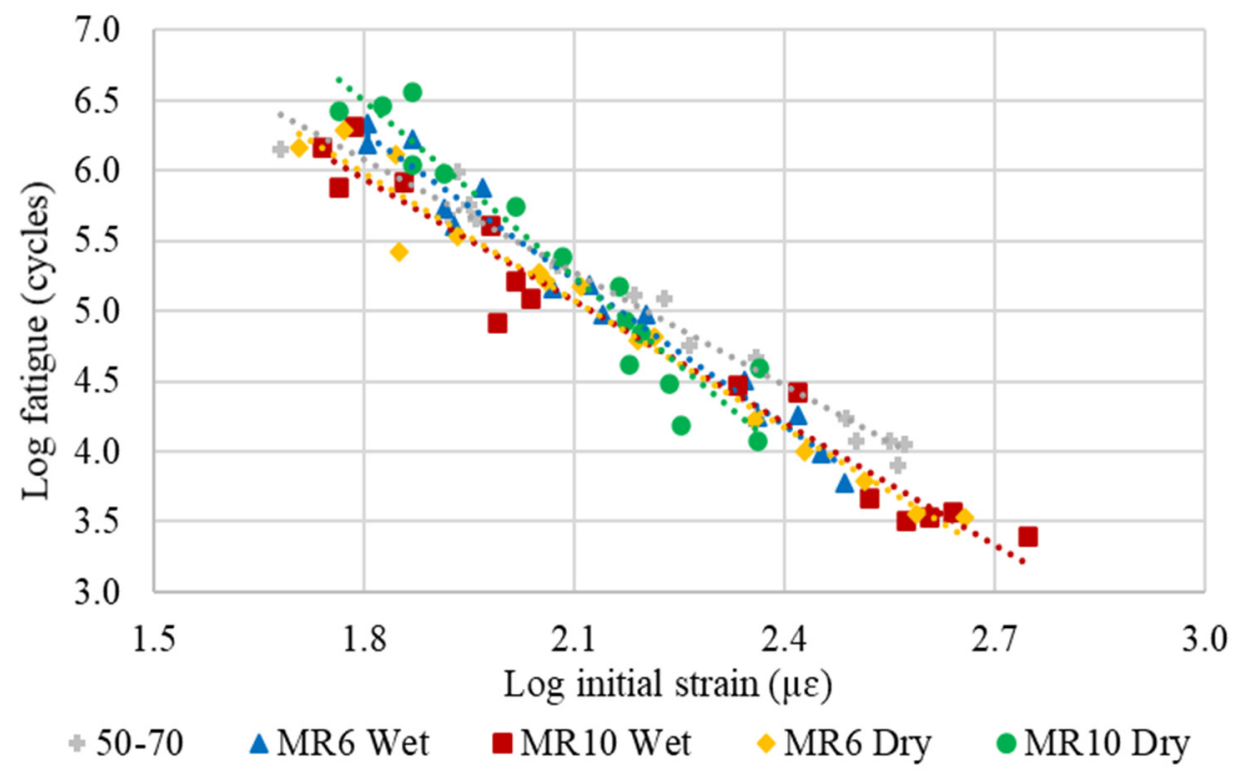

Figure 20. Effect of recycled plastic on UK DGA 10 fatigue life [26,28]. 


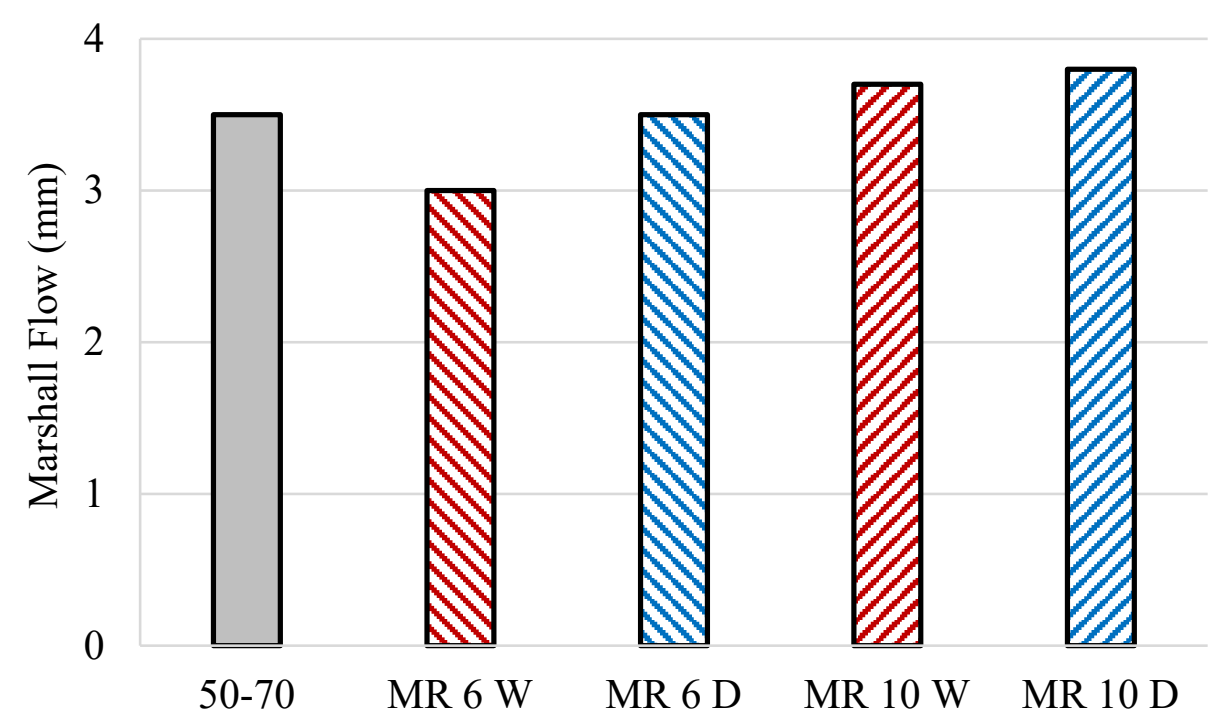

Figure 21. Effect of recycled plastic on UK DGA 10 Marshall Flow [26,28].

In Australia, the fatigue life of otherwise nominally identical DGA 10 was measured (in quadruplicate) for asphalt mixtures with and without recycled plastic modified asphalt binder [25]. Although the mixtures with recycled plastic had a lower average fatigue life (Figure 22), the results were not statistically significant, with $p$-values of 0.32 (for MR6) and 0.67 (for MR10). That is, recycled plastic modified asphalt binder did not significantly change the fatigue life of the asphalt mixtures. The same research also found no significant difference in the Marshall flow values for the unmodified and modified mixtures (Figure 23), with $p$-values of 0.61 (for MR6) and 0.39 (for MR10).

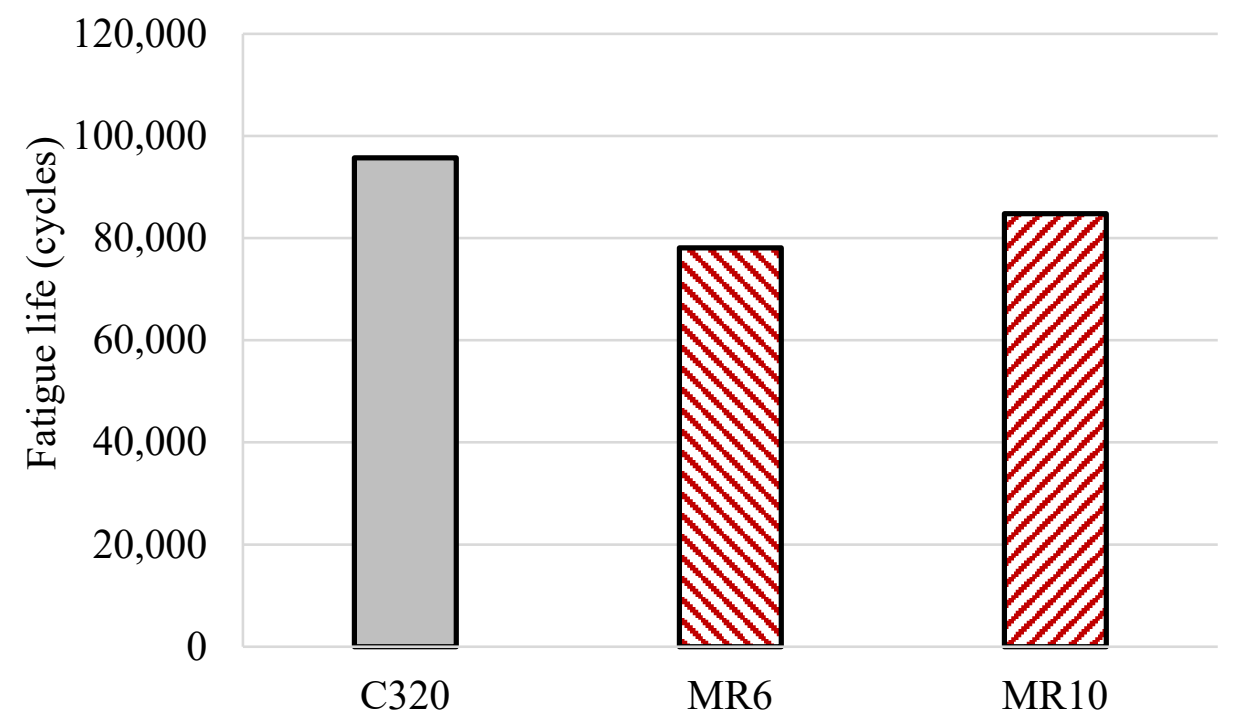

Figure 22. Effect of recycled plastic on average Australian DGA 10 fatigue life [25]. 


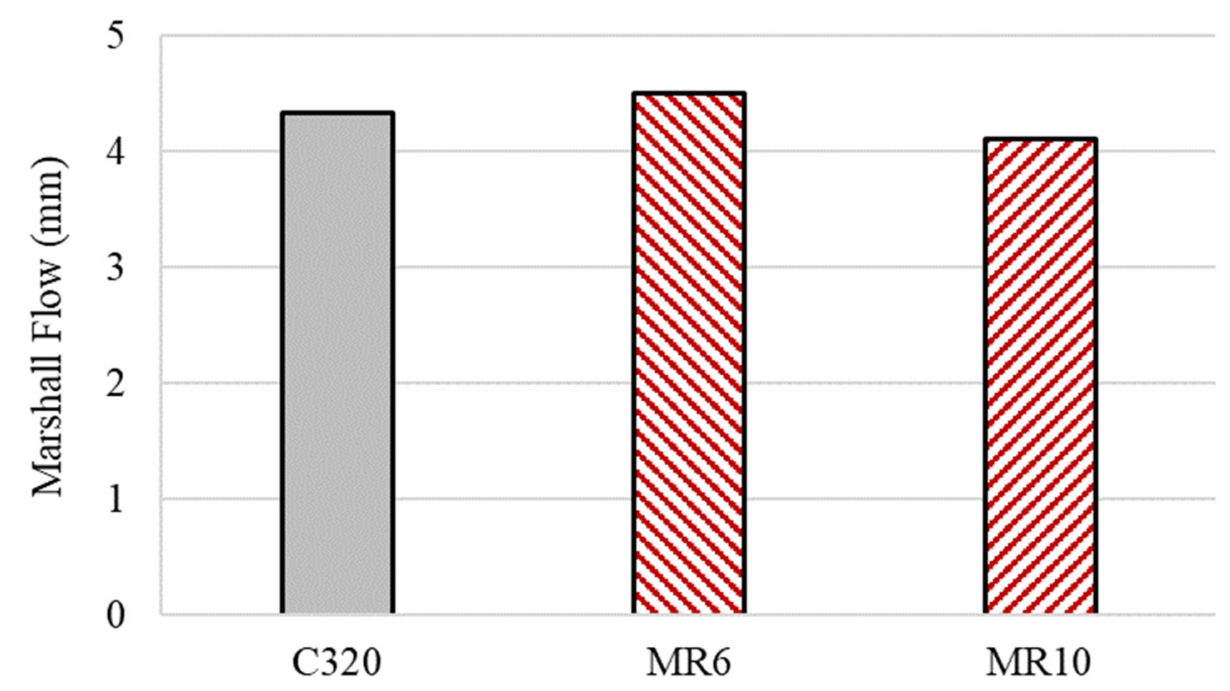

Figure 23. Effect of recycled plastic on average Australian DGA 10 Marshall Flow [25].

Based on the results of various asphalt mixture types commonly used in Australia and the UK, the addition of MR6 and MR10 were either associated with a moderate increase in crack resistance, or no significant change in crack resistance, when compared to otherwise identical unmodified mixtures. This is comparable to the effect of modification with conventional plastomeric polymers, such as EVA [19]. In contrast, conventional elastomeric polymers, such as SBS, are generally associated with significantly greater improvement in cracking resistance of asphalt mixtures.

\subsection{Moisture Damage Resistance}

Moisture damage resistance is commonly expressed as the tensile strength ratio (TSR), which is the ratio of the indirect tensile strength for conditioned and unconditioned samples, which is also known as the Lottman, or modified Lottman test, depending on the conditioning protocol. The TSR was calculated from tensile strength measurements for UK SMA 10 and DGA 20 [21], for UK DGA 10, by dry-mixing and wet-mixing [26,28], and for Australian DGA 10 [25]. In some cases, the TSR was lower for the recycled plastic modified mixtures, whereas in other cases, the TSR was higher for the recycled plastic modified mixtures (Figure 24). Overall, the effect of recycled plastic on TSR was not significant, with $p$-values of 0.72 and 0.52 , for MR6 and MR10, respectively. That is, the addition of recycled plastic did not significantly change the moisture damage resistance of the various asphalt mixtures.

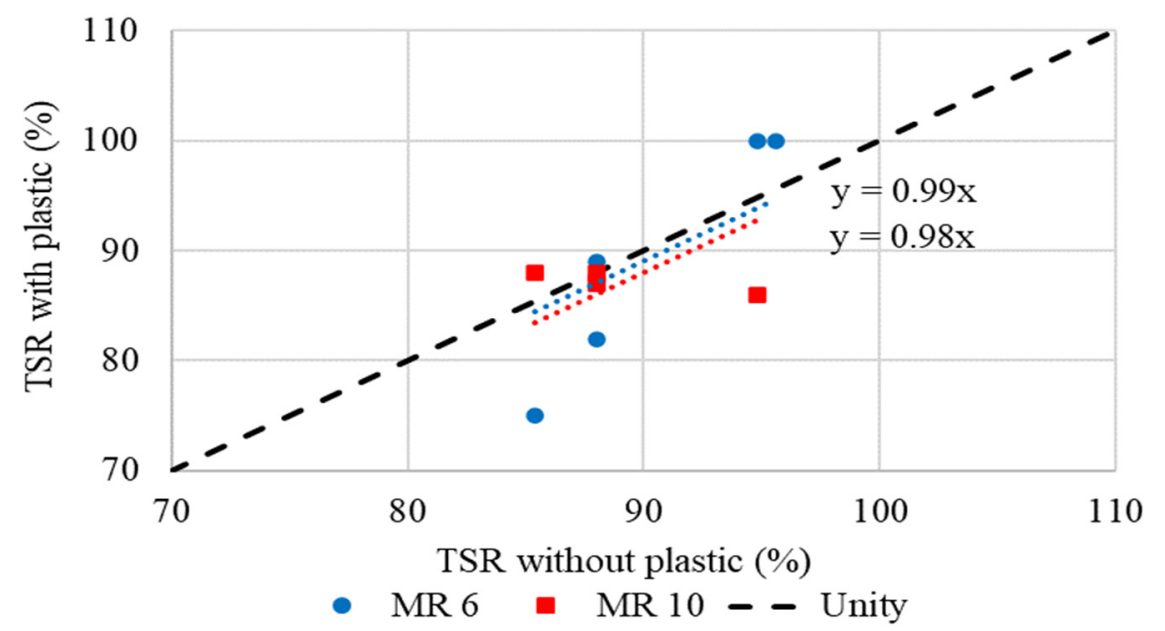

Figure 24. Effect of recycled plastic on mixture TSR value $[21,25,26,28]$. 


\section{Summary and Conclusions}

The commercially available recycled plastic products MR6 and MR10 for asphalt binder and asphalt mixture modification have been added to various unmodified bitumens and to various asphalt mixture types, and the effects measured using a range of tests commonly specified in Australia and the UK, as well as for PG rating system commonly used in the USA. Overall, the results were generally positive (Table 5). Recycled plastic products increased the resistance to asphalt binder flow and asphalt mixture deformation resistance. Significant ductility and elasticity were introduced to the asphalt binders, but the effect on asphalt mixture cracking resistance was either moderate or not significant. There was no significant difference in the asphalt mixture moisture damage resistance, but the mixture stiffness increased two- to three-fold. The effects of MR6 and MR10 were generally similar to the effects associated with conventional polymer modification of asphalt binders and asphalt mixtures, particularly those effects associated with the plastomeric polymer EVA [19].

Table 5. Summary of effects of recycled plastic on binder and mixtures.

\begin{tabular}{|c|c|}
\hline Property & Effect \\
\hline \multicolumn{2}{|r|}{ Binder properties } \\
\hline Resistance to flow & Significant increase in resistance to flow, based on penetration and viscosity \\
\hline Elasticity and ductility & $\begin{array}{l}\text { Incorporation of substantial elasticity and ductility that were negligible in the } \\
\text { unmodified asphalt }\end{array}$ \\
\hline Performance grading & Three (MR6) to four (MR10) grade increases based on the MSCR test protocol \\
\hline \multicolumn{2}{|r|}{ Mixture properties } \\
\hline Stiffness & $\begin{array}{l}\text { Two- to three-fold increase across various mixture types, based on various } \\
\text { measures of mixture modulus }\end{array}$ \\
\hline Deformation resistance & $\begin{array}{c}\text { Significant } 65 \% \text { (MR6) and } 43 \% \text { (MR10) reduction in wheel tracking rut depths for } \\
\text { various mixture types }\end{array}$ \\
\hline Crack resistance & $\begin{array}{c}\text { No significant reduction in fatigue life or fracture prorogation resistance, using } \\
\text { various test methods }\end{array}$ \\
\hline Moisture damage resistance & $\begin{array}{l}\text { No significant difference in resistance to moisture damage across various mixture } \\
\text { types, based on the Lottman test }\end{array}$ \\
\hline
\end{tabular}

Funding: This research received no external funding.

Acknowledgments: The support of MacRebur Ltd. is gratefully acknowledged and greatly appreciated.

Conflicts of Interest: The author declares no conflict of interest.

\section{References}

1. Sustainable Asphalt Pavements: A Practical Guide; National Asphalt Pavement Association: Greenbelt, MD, USA, 2019.

2. Jamshidi, A.; White, G. Use of recycled materials in pavement construction for environmental sustainability. In Proceedings of the Eighteenth Annual International Conference on Pavement Engineering, Asphalt Technology and Infrastructure, Liverpool, England, UK, 27-28 February 2019.

3. Jamshidi, A.; White, G. Evaluation of performance of challenges of use of waste materials in pavement construction: A critical review. Appl. Sci. 2020, 10, 226. [CrossRef]

4. White, G. Quantifying the impact of reclaimed asphalt pavement on airport asphalt surfaces. Constr. Build. Mater. 2019, 197, 757-765. [CrossRef]

5. Masad, E.; Roja, K.L.; Rehman, A.; Abdala, A. A Review of Asphalt Modification Using Plastics: A Focus on Polyethylene; Texas A\&M University: Qatar, Doha, 2020.

6. Yin, F.; Moraes, R.; Fortunatus, M.; Tran, N.; Elwardany, M.D.; Planche, J.-P. Performance Evaluation and Chemical Characterization of Asphalt Binder and Mixtures Containing Recycled Polyethylene; Plastic Industry Association: Washington, DC, USA, 2020. 
7. Ridden, P. The Streets of Vancouver Are Paved with ... . Recycled Plastic. New Atlas, 2012. Available online: http://newatlas.com/vancouver-recycled-plastic-warm-mix-asphalt/25254/ (accessed on 7 April 2019).

8. Saini, S. Forget Asphalt: A European City Is Building a Road Made Entirely out of Recycled Plastic. Business Insider, 2015. Available online: https://www.businessinsider.com.au/a-dutch-city-is-planning-to-buildroads-from-recycled-plastic-2015-7?r=US\&IR=T (accessed on 7 April 2019).

9. PTI. Jamshedpur's Plastic Roads Initiative Is a Lesson for All Indian Cities! India Times, 2015. Available online: http://www.indiatimes.com/news/india/every-indian-city-needs-to-learn-from-juscos-plastic-roadsin-jamshedpur-232246.html (accessed on 7 April 2019).

10. Parkes, R. Recycled Plastic Used in Airport Asphalt. Roads \& Infrastructure Australia, 2018. Available online: http://roadsonline.com.au/recycled-plastic-used-in-airport-asphalt/ (accessed on 7 April 2019).

11. Staff Writer. South Africa to Trial new 'Plastic-Road' Made from Recycled Materials. BusinessTech, 13 March 2019. Available online: https://businesstech.co.za/news/government/304992/south-africa-totrial-new-plastic-road-made-from-recycled-materials/ (accessed on 3 September 2020).

12. IPWEA. Soft Plastics from about 200,000 Plastic Bags and Packaging, and 63,000 Glass Bottle Equivalents Will Be Diverted from Landfill to Construct a Victorian Road. Institute of Public Works Australasia, 2018. Available online: http://www.ipwea.org/blogs/intouch/2018/05/29/this-australian-first-road-will-be-built-from-plas (accessed on 7 April 2019).

13. Topsfield, J. Plastic and Glass Road That Could Help Solve Australia's Waste Crisis. The Sydney Morning Herald, 2018. Available online: https://www.smh.com.au/environment/sustainability/plastic-and-glass-roadthat-could-help-solve-australia-s-waste-crisis-20180802-p4zv10.html (accessed on 7 April 2019).

14. Pisani, A. SA's First Recycled Road Made from Binned Plastic and Glass. 2018. Available online: http://www.news.com.au/national/south-australia/sas-first-recycled-road-made-from-binnedplastic-and-glass/news-story/e7f03a9b43f797e651256d6bc8a4fc90 (accessed on 7 April 2019).

15. Roberts, L. Canberra Roads to be Paved with Recycled Plastic as Government Rials New Type of Asphalt. Riotact! 5 March 2019. Available online: https:/the-riotact.com/canberra-roads-to-be-paved-with-recycledplastic-as-government-trials-new-type-of-asphalt/289498 (accessed on 3 September 2020).

16. Doyle, S. Plastic Road Trials Expanded by UK Government to stop Potholes. Engineering E Technology, 31 January 2019. Available online: https://eandt.theiet.org/content/articles/2019/01/plastic-road-trialsexpanded-by-uk-government-to-stop-potholes/ (accessed on 3 September 2020).

17. On the Road to Solving our Plastic Problem, UC San Diego News Center. 25 October 2018. Available online: https://ucsdnews.ucsd.edu/feature/on-the-road-to-solving-our-plastic---Problem (accessed on 3 September 2020).

18. Peters, A. Los Angeles is Testing 'Plastic Asphalt' that Makes It Possible to Recycle Roads. FastCompany, 24 October 2019. Available online: https://www.fastcompany.com/90420730/los-angeles-is-testing-plasticasphalt-that-makes-it-possible-to-recycle-roads (accessed on 3 September 2020).

19. Hunter, R.N.; Self, A.; Read, J. The Shell Bitumen Handbook, 6th ed.; ICE Publishing: Milan, Italy, 2015.

20. MacRebur Products. MacRebur, Lockerbie, Scotland, United Kingdom. Available online: www.macrebur. com/pdfs/product/MacReburProductSheet_v1.pdf (accessed on 7 April 2019).

21. White, G.; Reid, G. Recycled waste plastic for extending and modifying asphalt binders. In Proceedings of the 8th Symposium on Pavement Surface Characteristics (SURF 2018), Brisbane, Australia, 2-4 April 2018.

22. White, G. Evaluating recycled waste plastic modification and extension of bituminous binder for asphalt. In Proceedings of the Eighteenth Annual International Conference on Pavement Engineering, Asphalt Technology and Infrastructure, Liverpool, England, UK, 27-28 February 2019.

23. White, G.; Reid, G. Recycled waste plastic modification of bituminous binder. In Proceedings of the 7th International Conference on Bituminous Mixtures and Pavements, Thessaloniki, Greece, 12-14 June 2019.

24. White, G. Objective evaluation of the practical benefits of asphalt binders modified with recycled plastic. In Proceedings of the Asphalt Pavement '19, České Budějovice, Czech Republic, 26-27 November 2019.

25. White, G.; Magee, C. Laboratory evaluation of asphalt containing recycled plastic as a bitumen extender and modifier. J. Traffic Transp. Eng. 2019, 7, 218-235.

26. White, G.; Hall, F. Comparing wet mixed and dry mixed binder modification with recycled waste plastic. In Proceedings of the RILEM International Symposium on Bituminous Materials, Lyon, France, 14-16 December 2020; in press. 
27. White, G.; Reid, G. Recycled plastic as an alternate to conventional polymers for bituminous binder. In Proceedings of the 7th Eurasphalt and Eurobitume Congress, Madrid, Spain, 16-18 June 2021; in press.

28. White, G.; Hall, F. Laboratory Comparison of Wet-mixing and Dry-mixing of Recycled Waste Plastic for Binder and Asphalt Modification. In Proceedings of the 100th TRB Annual Meeting: A Virtual Event, January 2021; in press.

29. Characterization of Modified Asphalt Binders in Superpave Mix Design; National Cooperative Highway Research Program, Report 459; Transportation Research Board: Washington, DC, USA, 2001.

30. The Multiple Stress Creep Recovery (MSCR) Procedure; Technical Brief FHWA-HIF-11-038; Federal Highways Administration: Washington, DC, USA, April 2011. Available online: http://www.fhwa.dot.gov/pavement/ materials/pubs/hif11038/hif11038.pdf (accessed on 8 February 2015).

31. White, G. Grading highly modified binders by multiple stress creep recovery. Road Mater. Pavement Des. 2017, 18, 1322-1327. [CrossRef]

32. Kaloush, K.E. Simple Performance Test. for Permanent Deformation of Asphalt Mixtures. Ph.D. Thesis, Arizona State University, Tempe, AZ, USA, May 2001.

Publisher's Note: MDPI stays neutral with regard to jurisdictional claims in published maps and institutional affiliations.

(C) 2020 by the author. Licensee MDPI, Basel, Switzerland. This article is an open access article distributed under the terms and conditions of the Creative Commons Attribution (CC BY) license (http://creativecommons.org/licenses/by/4.0/). 